\title{
Comprehensive Structure Characterization of Lipid A Extracted from Yersinia pestis for Determination of its Phosphorylation Configuration
}

\author{
Jace W. Jones, ${ }^{\text {a }}$ Ilana E. Cohen, ${ }^{\text {b }}$ František Tureček, ${ }^{c}$ David R. Goodlett, ${ }^{\text {a }}$ \\ and Robert K. Ernst ${ }^{\text {b,d }}$ \\ ${ }^{a}$ Department of Medicinal Chemistry, University of Washington, Seattle, Washington, USA \\ ${ }^{b}$ Department of Medicine, University of Washington, Seattle, Washington, USA \\ ${ }^{\mathrm{c}}$ Department of Chemistry, University of Washington, Seattle, Washington, USA \\ d Department of Microbial Pathogenesis, School of Dentistry, University of Maryland-Baltimore, Baltimore, \\ Maryland, USA
}

We report on comprehensive structure characterization of lipid A extracted from Yersinia pestis $(Y p)$ for determination of its phosphorylation configuration that was achieved by combining the methods of molecular biology with high-resolution tandem mass spectrometry. The phosphorylation pattern of diphosphorylated lipid A extracted from $Y p$ has recently been found to be a heterogeneous mixture of C-1 and C-4' bisphosphate, $\mathrm{C}-1$ pyrophosphate, and C-4' pyrophosphate (Proc. Natl. Acad. Sci. 2008, 105, 12742). To reduce the inherent phosphate heterogeneity of diphosphorylated lipid A extracted from Yp, we incorporated specific C-1 and $\mathrm{C}^{\prime} 4^{\prime}$ position phosphatases into wild type KIM6+Yp grown at $37^{\circ} \mathrm{C}$. Comprehensive high-resolution tandem mass spectrometric analyses of lipid A extracted from $Y p$ modified with either the C-1 or C-4' phosphatase allowed for unambiguous structure assignment of monophosphorylated and diphosphorylated lipid A and distinction of isomeric bisphosphate and pyrophosphate forms. The prevalent aminoarabinose modification was determined to be exclusively attached to the lipid A disaccharide via a phospho-diester linkage at either or both the C-1 and C-4' positions. (J Am Soc Mass Spectrom 2010, 21, 785-799) (C) 2010 Published by Elsevier Inc. on behalf of American Society for Mass Spectrometry

$\mathrm{L}$ ipopolysaccharide (LPS) constitutes the majority of the outer leaflet of the outer membrane of gram-negative bacteria and represents one of the major microbial molecular signals responsible for activation of the mammalian innate immune system [1]. Recognition of LPS, in particular its bioactive component lipid A, has provided mammalian immune systems with a key strategy for defense against many gram-negative pathogens [2]. For instance, it has been linked to the induction of inflammation, targeting of bacteria for elimination, and clearance and detoxification of LPS [3]. Recognition of LPS by the mammalian innate immune system occurs via the pattern recognition receptor Toll-like receptor 4 (TLR4), in conjunction with myeloid differentiation-2 (MD-2) [4-7]. Two accessory proteins, LPS-binding protein (LBP) and CD14, facilitate the transfer of LPS from the bacterial membrane to the TLR4-MD-2 heterodimer complex [8-10]. Binding of LPS to TLR4-MD-2 induces site-specific dimerization believed to play a vital role in activation

Address reprint requests to Dr. R. K. Ernst, Department of Microbial Pathogenesis, School of Dentistry, University of Maryland-Baltimore, 650 W. Baltimore St. 8 South, Baltimore, MD 21201, USA. E-mail: rkernst@ maryland.edu of the TLR4 recognition pathway [11]. The precise arrangement of the TLR4-MD-2-LPS complex leading to induced conformational dimerization was determined to involve explicit hydrophobic, ionic, and hydrogen bonding interactions, all of which rely heavily on lipid A structure [11].

The enzymes required for the biosynthesis of lipid A are highly conserved [12]. Yet, structural analysis of lipid A within individual organisms resulting from different growth conditions (e.g., temperature) as well as among various organisms yields a remarkable amount of variation [1]. Lipid A diversity has been attributed to the action of "latent" enzymes that modify the biochemically conserved lipid A molecule [1, 12]. Variation in lipid A structure may contribute to bacterial virulence either by mitigating early innate immune defense responses to infection [13], presumably by evading TLR4 detection, or by intensifying inflammatory responses that ensue when local infection is not contained [2], presumably by over-stimulation of the TLR4 recognition pathway. The crucial factors in lipid A structure that affect TLR4 activation include phosphorylation patterns and acylation configurations $[11,14,15]$. 
The phosphorylation pattern of lipid A has been shown to be important for its biological activity. For example, high-resolution crystallography demonstrated that the C-1 and C-4' phosphate groups on lipid A bind to basic amino acid residues on TLR4 and MD-2, playing a crucial role in dimerization of the TLR4-MD2-LPS heterodimer complex [11]. Removal of a phosphate group has been shown to substantially reduce lipid A toxicity [16, 17] and interleukin-1 induction capacity [15], whereas masking of lipid A phosphate groups (e.g., by addition of aminoarabinose moieties, Ara4N) has been shown to affect bacterial resistance to host cationic antimicrobial peptides [18-21].

A number of pathogens producing significant human disease synthesize lipid A molecules that are poorly recognized by the human innate immune system [13]. One such poorly recognized pathogen is Yersinia pestis $(Y p)[14,22]$. Yp is a highly invasive and often lethal gram-negative bacterium that is transmitted to the mammalian host by either fleabite or inhalation of an infectious droplet [23]. At the mammalian host temperature of $37^{\circ} \mathrm{C}$, the major lipid A structure consists of a $\beta$-1,6-linked diglucosamine disaccharide with two phosphate groups, and four primary 3hydroxymyristic acid $(\mathrm{C} 14(3-\mathrm{OH}))$ acyl chains [2428]. Additionally, $Y p$ lipid A is heavily modified with one or two Ara4N moieties [29].

Recently, we reported that diphosphorylated lipid A structures extracted from numerous gram-negative pathogens, including $Y p$ grown at $37^{\circ} \mathrm{C}$, are a heterogeneous mixture of bisphosphate and pyrophosphate molecules [29]. Although the presence of pyrophosphate was confirmed, the extent and localization of the pyrophosphate moiety remained unclear. Moreover, this diverse phosphorylation configuration also led to ambiguous assignment of the Ara $4 \mathrm{~N}$ substituents. In this report, we utilized a tandem mass spectrometric approach to analyze $Y p$ strains that expressed Francisella novicida lipid A C-1 position or C-4' position phosphatase enzymes to investigate the resultant lipid A pattern extracted from $Y p$. Reducing the extent and therefore the complexity of phosphorylation in $Y p$ by incorporation of the specific phosphatase enzymes not only enabled us to comprehensively characterize the phosphate configuration but also provided a means for localization of the Ara4N moieties.

\section{Experimental}

\section{Bacterial Strains and Growth Conditions}

Yersinia pestis KIM6+ [30] was grown in Luria broth, $\mathrm{pH} 7.4$, at $37^{\circ} \mathrm{C}$ with aeration and harvested in the late exponential phase. $Y p \mathrm{KIM} 6+$ grown at $37^{\circ} \mathrm{C}$ will be designated as wild type $\left(Y p W T \_37^{\circ} \mathrm{C}\right)$. Lipid A C-1 and C-4' phosphatase enzymes, LpxE and LpxF, have been expression cloned in Francisella novicida [31, 32] and were kindly provided by Dr. C. R. H. Raetz of Duke University. The individual plasmids containing the structural genes for LpxE or LpxF and an ampicillin resistance gene were incorporated into $\mathrm{KIM} 6+$ via electroporation. The phosphatase expressing strains of $Y p$ KIM6+ were grown in Luria broth supplemented with ampicillin $(100 \mu \mathrm{g} / \mathrm{mL}), \mathrm{pH} 7.4$, at $37^{\circ} \mathrm{C}$ with aeration and harvested in the late exponential phase, and referred to as $Y p L p x E \_37^{\circ} \mathrm{C}$ and $Y p L p x F \_37^{\circ} \mathrm{C}$.

\section{LPS Purification and Lipid A Isolation}

$Y p$ LPS was extracted using a hot phenol/water extraction method [33]. Further treatment of LPS with RNase A, DNase I, and proteinase $\mathrm{K}$ ensured removal of contaminating nucleic acids and proteins [34]. Hydrolysis of LPS to isolate lipid A was accomplished with $1 \%$ sodium dodecyl sulfate (SDS) at $\mathrm{pH} 4.5$ as described [35].

\section{Electrospray Ionization-Linear Ion Trap-Fourier Transform Ion Cyclotron Resonance Mass Spectrometry}

Lipid A was analyzed by electrospray ionization (ESI) in the negative ion mode on a LTQ-FT linear ion trap Fourier transform ion cyclotron resonance mass spectrometer (Thermo Scientific, San Jose, CA). Samples were diluted to $1.0 \mathrm{mg} / \mathrm{ml}$ in chloroform/methanol $(1: 1, \mathrm{vol} / \mathrm{vol})$ and infused at a rate of $1.0 \mathrm{~mL} / \mathrm{min}$ via a fused silica capillary (75 $\mu \mathrm{m}$ i.d./360 $\mu \mathrm{m}$ o.d.) with a 30 $\mu \mathrm{m}$ spray tip (New Objective, Woburn, MA). Instrument calibration and tuning parameters were optimized using a solution of Ultramark 1621 (Lancaster Pharmaceuticals, PA) in both positive and negative ion modes. For experiments acquired in the ion cyclotron resonance (ICR) cell, the mass resolving power was set to 100,000 and ion populations were held constant by automatic gain control at $1.0 \times 10^{6}$ for mass spectra (MS) acquisition and at $5.0 \times 10^{5}$ for tandem mass spectra $\left(\mathrm{MS}^{n}\right)$, respectively. For tandem mass spectra, the precursor ion selection window was set to 4-8 $\mathrm{Da}$ and the collision energy was set to $30 \%$ on the instrument scale. The collision-induced dissociation (CID) $\mathrm{MS}^{n}$ analyses in the linear ion trap were acquired with an ion population of $1.0 \times 10^{4}$ and maximum fill time of $200 \mathrm{~ms}$. The subsequent $\mathrm{MS}^{2}, \mathrm{MS}^{3}$, and $\mathrm{MS}^{4}$ events had an isolation window of $2 \mathrm{Da}$ with a collision energy of $25 \%$. All spectra were acquired over a time period of 1-2 min and averaged. Typically, MS events were mass analyzed in the ICR cell and $\mathrm{MS}^{2}, \mathrm{MS}^{3}$, and $\mathrm{MS}^{4}$ events were mass analyzed in the LTQ. Infrared multiphoton dissociation (IRMPD) $\mathrm{MS}^{2}$ events were acquired in the ICR cell using similar detection parameters as described above. Precursor ions were irradiated by IR photons produced by a $\mathrm{CO}_{2}$ laser (Synrad Firestar series V20, Mukilteo, WA, USA, model FSV20SFB 75 W [10.2-10.8 $\mu \mathrm{m}])$ with pulse durations of 20 to $100 \mathrm{~ms}$ and pulse power of 20 to $80 \%$. Data were acquired and processed 
using Xcalibur, version 1.4 (Thermo Scientific, San Jose, CA, USA) utilizing 7-point Gaussian smoothing.

\section{Results}

We now describe the experiments comparing the mass and $\mathrm{MS}^{n}$ tandem mass spectra of lipid A forms from wild type, LpxE, and LpxF strains that were used to distinguish the isomeric diphosphate and pyrophosphate groups, determine their positions and those of Ara $4 \mathrm{~N}$ moieties, and to estimate the extent of pyrophosphorylation.

\section{ESI LTQ-FT MS of Lipid A Extracted from}

Yersinia pestis Wild Type, LpxE, and LpxF

Grown at $37^{\circ} \mathrm{C}$

The negative ion mode ESI LTQ-FT mass spectra of lipid A extracted from $Y p$ wild type $\left(Y p W T \_37^{\circ} \mathrm{C}\right), Y p$

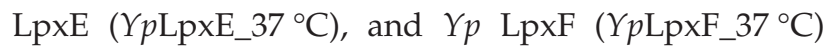
grown at $37^{\circ} \mathrm{C}$ are shown in Figure 1a-c. The two most abundant ions at $m / z 1535$ and 1666 from the YpWT_37 ${ }^{\circ} \mathrm{C}$ mass spectrum (Figure 1a) corresponded to singly deprotonated ions that were diphosphoryl tetra-acylated with the addition of one and two Ara4N units, respectively. Note that Ara $4 \mathrm{~N}$ is added to the phosphate group as a dehydrated carbohydrate unit, $\Delta \mathrm{m}($ Ara4N $)=131.05,824$ Da for $\mathrm{C}_{5} \mathrm{H}_{9} \mathrm{NO}_{3}$. All tetraacylated lipid A structures discussed hereinafter consist of four primary 3-hydroxymyristic acyl chains, denoted by $\mathrm{C} 14(3-\mathrm{OH})$. As noted previously, the diphosphorylated lipid A structure was a heterogeneous mixture of both bisphosphate and pyrophosphate [29]. Several other less abundant singly charged ions involving tetra-acylated configurations were present at $\mathrm{m} / \mathrm{z} 1455$ (monophosphoryl with one Ara4N), 1404 (diphosphoryl), and 1324 (monophosphoryl). A series of prominent singly charged anions indicating the presence of penta-

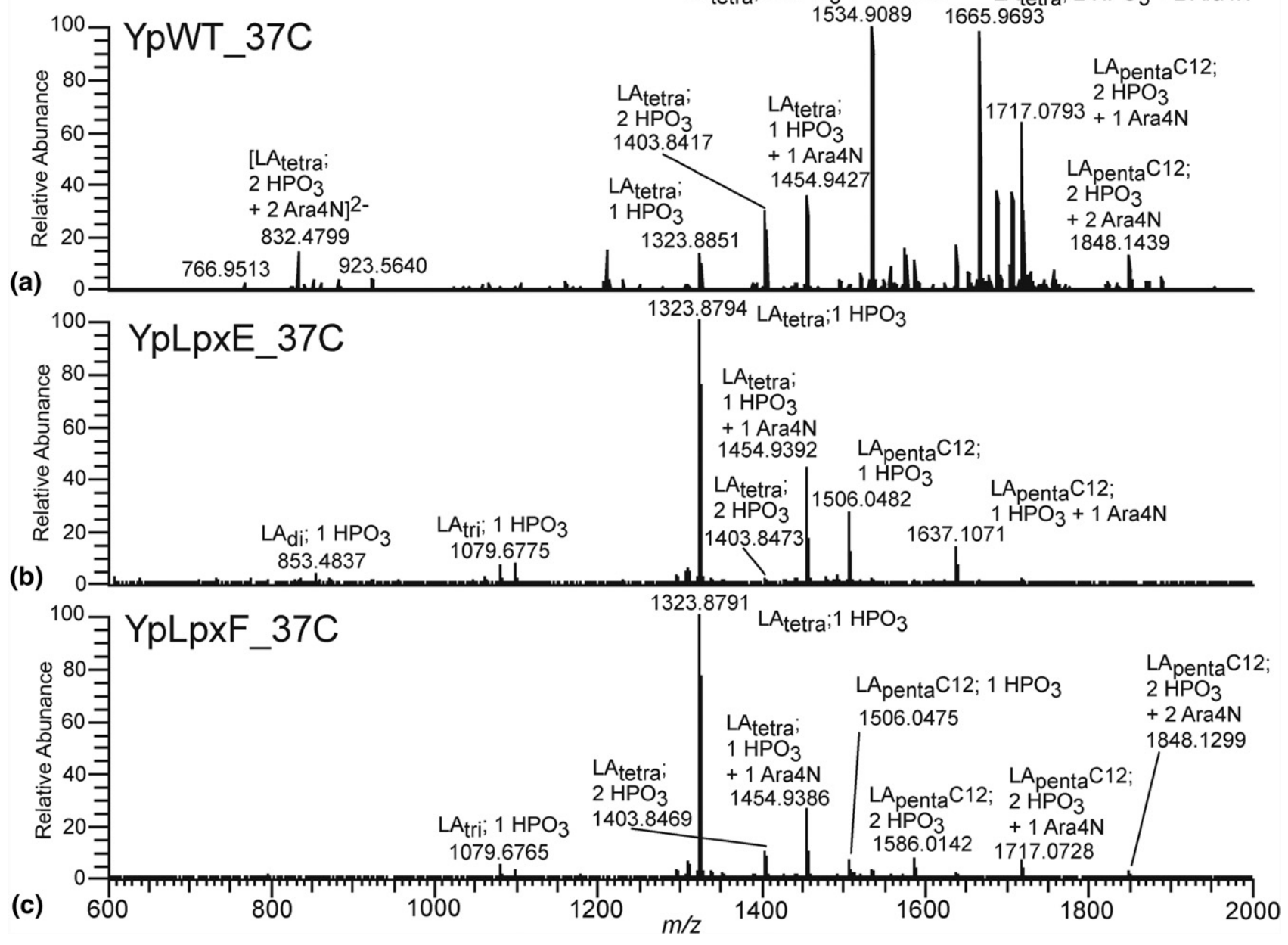

Figure 1. Negative ion mode ESI LTQ-FT mass spectrum of lipid A from (a) $Y p W T \_37^{\circ} \mathrm{C}$, (b) $Y p \operatorname{LpxE} 337^{\circ} \mathrm{C}$, and (c) $Y p \operatorname{LpxF} 37^{\circ} \mathrm{C}$. All ions are singly charged unless noted otherwise. Shorthand notation is as follows: $\mathrm{LA}=$ lipid $\mathrm{A}$; di = di-acylated; tri = tri-acylated; tetra $=$ tetra-acylated; penta $=$ penta-acylated $\mathrm{HPO}_{3}=$ phosphate group; $\mathrm{Ara} 4 \mathrm{~N}=$ dehydroaminoarabinose; $\mathrm{C} 12$ = lauric acid; all acyl chains are 3-hydroxymyristic acid $(\mathrm{C} 14(3-\mathrm{OH}))$ except for the penta-acylated Lipid A ions for which one additional lauric acid residue is included. 
acylated lipid A forms were found at $m / z 1586$ (diphosphoryl), 1717 (diphosphoryl with one Ara4N), and 1848 (diphosphoryl with two Ara4N). Penta-acylated lipid A contained four primary acyl chains (all C14(3-OH)) and one secondary acyl chain (C12:0) presumably attached to the C-3' primary $\mathrm{C} 14(3-\mathrm{OH})$ in an acyloxyacyl arrangement and hereafter referred to as penta-acylated_C12 [29]. In addition to singly charged precursor ions, doubly charged precursor ions were also present in the Figure 1a mass spectrum in the $m / z 700-1000$ range, albeit at a lower relative abundance. Doubly charged ions at $\mathrm{m} / \mathrm{z}$ 767,832 , and 923 corresponded to diphosphoryl tetraacylated lipid A with one and two Ara4N modifications and diphosphoryl penta-acylated_C12 lipid A with two Ara4N modifications, respectively. All relevant singly and doubly charged precursor ions from Figure 1a were identified by their elemental composition based on accurate mass measurements [Supporting Information (SI), which can be found in the electronic version of this article (SI Table S1)].

In contrast to the $Y p \mathrm{WT} \_37^{\circ} \mathrm{C}$ mass spectrum (Figure 1a), the mass spectrum for $Y p \operatorname{LpxE} \_37^{\circ} \mathrm{C}$ (Figure $1 b$ ) displayed the most intense peak of an $\mathrm{m} / z 1324$ ion corresponding to a singly charged monophosphoryl tetra-acylated lipid A species. Further investigation of the $Y p$ LpxE_ $37^{\circ} \mathrm{C}$ mass spectrum (Figure $1 \mathrm{~b}$ ) revealed several other abundant singly charged ions at $\mathrm{m} / \mathrm{z} 1455$, 1506, and 1637 that were all monophosphorylated. These ions corresponded to the following respective species: monophosphoryl tetra-acylated with one Ara $4 \mathrm{~N}$, monophosphoryl penta-acylated_C12, and monophosphoryl penta-acylated_C12 with one Ara4N. The aforementioned monophosphoryl ions demonstrated the effectiveness of LpxE to remove one phosphate group from both diphosphoryl tetra-acylated and diphosphoryl penta-acylated_C12 Yp lipid A. Although at low abundance, ions at $\mathrm{m} / \mathrm{z} 1404$ and 1535 were present, indicating the existence of diphosphoryl tetra-acylated lipid A structures in the $Y p$ LpxE_3 $37^{\circ} \mathrm{C}$ mass spectrum (Figure 1b). At this particular point, it remained unclear as to whether the diphosphorylated lipid A structures were a result of pyrophosphorylated lipid A or inefficient phosphatase activity. In contrast to the $Y p \mathrm{WT} \_37^{\circ} \mathrm{C}$ mass spectrum, the YpLpxE_37 ${ }^{\circ} \mathrm{C}$ mass spectrum did not yield any doubly charged precursor ions presumably because of missing doubly phosphorylated species. All relevant precursor ions from Figure $1 \mathrm{~b}$ were identified by their respective elemental composition (SI Table S2).

Similar to the $Y p$ LpxE_3 $3{ }^{\circ} \mathrm{C}$ mass spectrum (Figure $1 b$ ), the $Y p$ LpxF_3 $3{ }^{\circ} \mathrm{C}$ mass spectrum (Figure 1c) displayed the most intense peak for an ion at $\mathrm{m} / \mathrm{z} 1324$. Comparison of the $Y p L p x F \_37^{\circ} \mathrm{C}$ mass spectrum (Figure 1c) to the $Y p W T \_37^{\circ} \mathrm{C}$ mass spectrum (Figure 1a) demonstrated the effectiveness of LpxF in removing one phosphate group from diphosphoryl $Y p$ lipid A. All precursor ions identified in the $Y p \operatorname{LpxF} \_37^{\circ} \mathrm{C}$ mass spectrum (SI Table S3) were also identified in the Y $p$ LpxE_ $37^{\circ} \mathrm{C}$ mass spectrum (SI Table S2) but the ion relative abundances, excluding that of the $\mathrm{m} / \mathrm{z} 1324$ ion, were shifted noticeably. The singly charged monophosphorylated ions at $m / z$ 1455, 1506, and 1637 were fairly abundant in the $Y p \operatorname{LpxE} \_37^{\circ} \mathrm{C}$ mass spectrum whereas these particular ions in the $Y p L p x F \_37^{\circ} \mathrm{C}$ mass spectrum were at considerably lower relative abundance. More striking, the diphosphorylated ions at $\mathrm{m} / \mathrm{z} 1404$, 1535, 1586, 1717, and 1848 had a much higher relative abundance in the $Y p$ LpxF_ $37^{\circ} \mathrm{C}$ mass spectrum than in the $Y p \operatorname{LpxE} \_37^{\circ} \mathrm{C}$ mass spectrum. As was the case for the $Y p$ LpxE_ $37{ }^{\circ} \mathrm{C}$ mass spectrum, the $Y p$ LpxF_37 ${ }^{\circ} \mathrm{C}$ mass spectrum did not yield any doubly charged precursor ions. All relevant precursor ions from Figure 1c were identified in SI Table S3.

\section{Determination of Phosphate Location in Monophosphoryl Tetra-Acylated Lipid A from YpLpxE_37 ${ }^{\circ} \mathrm{C}$ and $\mathrm{YpLpxF} 37^{\circ} \mathrm{C}$}

To determine the phosphate location in monophosphoryl tetra-acylated lipid A from $Y p$ LpxE_37 ${ }^{\circ} \mathrm{C}$ and $Y p L p x F \_37^{\circ} \mathrm{C}$ and thus test the specificity of the phosphatase enzymes, we performed a series of tandem mass spectrometry experiments on monophosphorylated precursor ions at $\mathrm{m} / \mathrm{z} 1324$ from both $Y p$ LpxE_ $37^{\circ} \mathrm{C}$ and $Y p L p x F \_37^{\circ} \mathrm{C}$. The infrared multiphoton dissociation (IRMPD) tandem mass spectra for $\mathrm{m} / \mathrm{z} 1324$ ions from both $Y p$ LpxE_37 ${ }^{\circ} \mathrm{C}$ and $Y p L p x F \_37^{\circ} \mathrm{C}$ were recorded with an ESI LTQ-FT mass spectrometer and are shown in Figure 2. The same experimental parameters, including fragmentation conditions (i.e., irradiation time and duration), were employed for both $Y p$ LpxE_ $37^{\circ} \mathrm{C}$ and $Y p \operatorname{LpxF} 37^{\circ} \mathrm{C}$ mass spectra. Comparison of the two mass spectra (Figure 2) revealed several critical differences in the presence and relative abundance of the observed product ions.

The $Y p$ LpxE_ $37^{\circ} \mathrm{C}$ IRMPD tandem mass spectrum of the $m / z 1324$ ion (Figure 2a) displayed a series of A-type cross-ring fragment ions at $m / z 1039\left({ }^{0,2} \mathrm{~A}_{2} \_1 \mathrm{HPO}_{3}\right), 794$ $\left({ }^{0,2} \mathrm{~A}_{2}-\mathrm{C} 14(3-\mathrm{OH}) \_1 \mathrm{HPO}_{3}\right), 752\left({ }^{0,4} \mathrm{~A}_{2-} 1 \mathrm{HPO}_{3}\right)$, and 508 $\left({ }^{0,4} \mathrm{~A}_{2}-\mathrm{C} 14(3-\mathrm{OH}) \_1 \mathrm{HPO}_{3}\right)$ which all contained one phosphate group and were absent in the IRMPD tandem mass spectrum of $Y p L p x F \_37^{\circ} \mathrm{C}$ (Figure $2 b$ ). Notation for ring-cleavage fragments follows nomenclature outlined by Domon and Costello [36]. Salient differences between the $Y p L p x E \_37^{\circ} \mathrm{C}$ and $Y p L p x F \_37^{\circ} \mathrm{C}$ IRMPD tandem mass spectra were observed for several fragment ions, e.g., $m / z 1080,895,853$, etc. Specifically, the fragment ions at $\mathrm{m} / \mathrm{z} 895$ and 651 are more abundant in the $Y p L p x F \_37^{\circ} \mathrm{C}$ mass spectrum (Figure 2a) compared to the same ions in the $Y p L p x E \_37^{\circ} \mathrm{C}$ mass spectrum (Figure 2b). These product ions corresponded to an aldehyde elimination (loss of $\mathrm{C}_{12} \mathrm{H}_{24} \mathrm{O}$ from C14(3-OH)) and neutral loss of one or two acyl chains as alkane carboxylic acids from the precursor ion, respectively. Furthermore, the ratio of ion intensities in the series at $m / z 853$ and 835 was decidedly different between the $Y p$ LpxE_37 ${ }^{\circ} \mathrm{C}$ and $Y p L p x F \_37^{\circ} \mathrm{C}$ IRMPD tandem mass spectra, whereby the ratio of ion intensities 


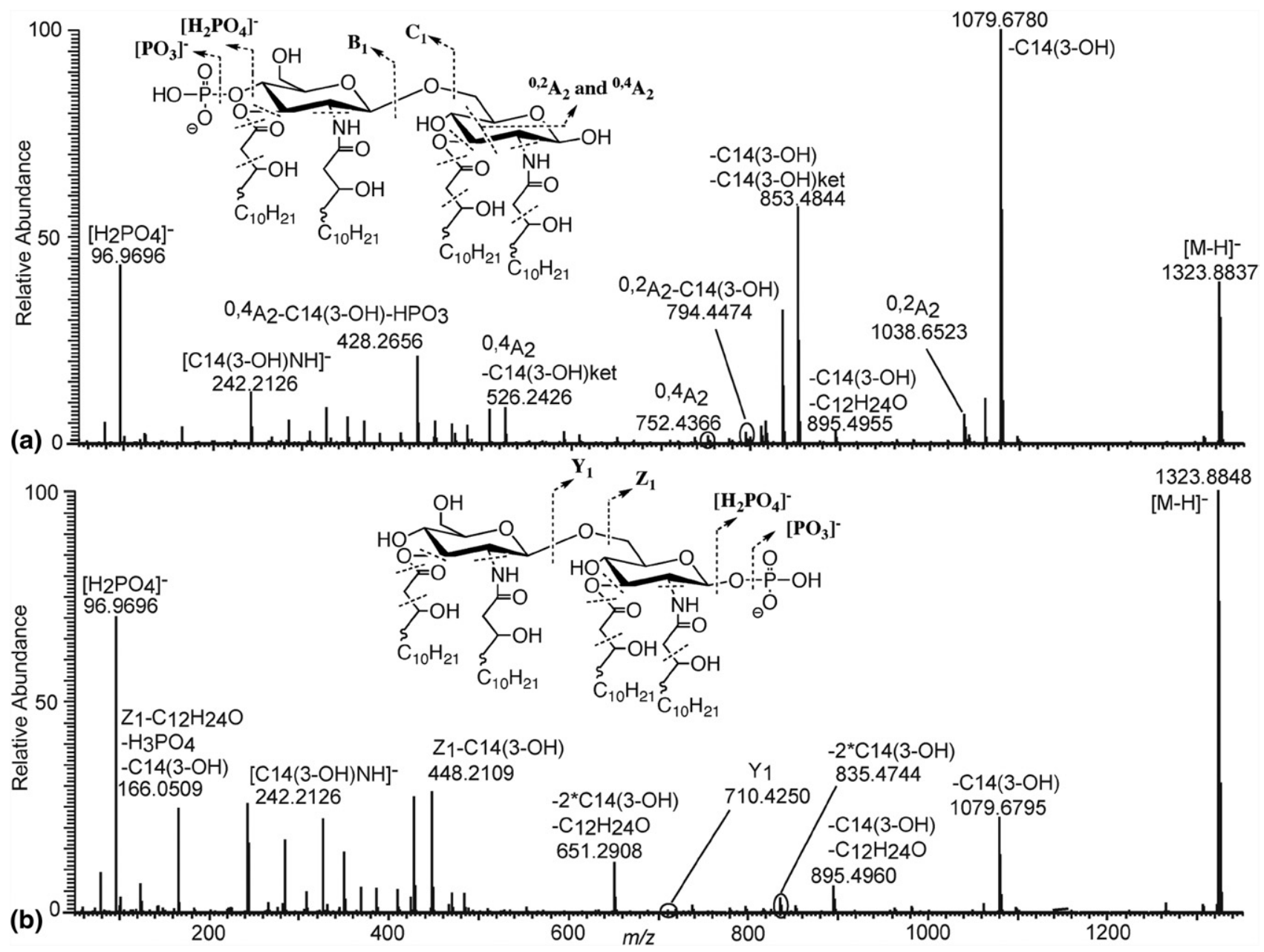

Figure 2. Negative ion mode ESI LTQ-FT IRMPD MS ${ }^{2}$ mass spectrum of the ion at $\mathrm{m} / \mathrm{z} 1324$ from (a) $Y p L p x E \_37^{\circ} \mathrm{C}$, and (b) $Y p L p x F \_37^{\circ} \mathrm{C}$. Inset structures show the proposed phosphate positioning and dashed lines indicate possible cleavage sites. $\mathrm{C} 14(3-\mathrm{OH})$ represents acyl chain loss as an alkyl carboxylic acid and C14(3-OH)ket represents acyl chain loss as an alkyl ketene.

at $m / z$ 853:835 was 2:1 for $Y p L p x E \_37^{\circ} \mathrm{C}$ and $1: 2$ for $Y p L p x F \_37^{\circ} \mathrm{C}$. The fragment ion at $\mathrm{m} / \mathrm{z} 853$ resulted from a neutral loss of two acyl chains, one as an alkane carboxylic acid and one as an alkyl ketene. The fragment ion at $m / z 835$ was a result of neutral loss of two acyl chains both as alkane carboxylic acids. An alternative dissociation technique, collision-induced dissociation (CID) involving multi-stage MS, also confirmed the difference in the dissociation of the precursor ion at $\mathrm{m} / \mathrm{z}$ 1324 from $Y p L p x E \_37^{\circ} \mathrm{C}$ and $Y p L p x F \_37^{\circ} \mathrm{C}$. These results are shown in SI Figure S1 for $\mathrm{MS}^{2}$ of the $m / z 1324$ ion and in SI Figure S2 for $\mathrm{MS}^{3}$ of the $\mathrm{m} / \mathrm{z} 1080$ ion (derived from the $\mathrm{m} / \mathrm{z} 1324$ precursor ion by elimination of hydroxymyristic acid).

Dissociation analyses of the singly phosphorylated precursor ion at $m / z 1324$ from $Y p L p x E \_37^{\circ} \mathrm{C}$ and $Y p L p x F \_37^{\circ} \mathrm{C}$ yielded distinctly different tandem mass spectra. To explain the difference in dissociation mass spectra for the precursor ion at $\mathrm{m} / \mathrm{z} 1324$, one must

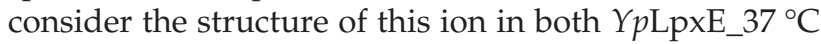
and $Y p L p x F \_37^{\circ} \mathrm{C}$. The most salient aspect of the analyses lies in the presence and absence of A-type product ions containing the phosphate group. Observation of these diagnostic product ions in $Y p$ LpxE_ $37^{\circ} \mathrm{C}$ tandem mass spectra unambiguously put the phosphate group at the $\mathrm{C}-4^{\prime}$ position in YpLpxE_37 ${ }^{\circ} \mathrm{C}$. Conversely, lack of these diagnostic product ions in Y p L pxF_37 ${ }^{\circ} \mathrm{C}$ tandem mass spectra clearly demonstrated that the phosphate was located at the C-1 position in $Y p$ LpxF_ $37^{\circ} \mathrm{C}$. Furthermore, the phosphate position, which determines the location of negative charge in the ion, influenced the fragmentation pathways upon dissociation of lipid A anions. For example, the relative intensity of product ions resulting from neutral loss of acyl chains as an aldehyde elimination depended on the phosphate location. When the phosphate group was at the $\mathrm{C}-1$ position $\left(Y p \operatorname{LpxF} 37^{\circ} \mathrm{C}\right)$, neutral loss of $\mathrm{C}_{12} \mathrm{H}_{24} \mathrm{O}$ from $\mathrm{C} 14(3-\mathrm{OH})$ was substantially more abundant than when the phosphate group was at the $\mathrm{C}-4^{\prime}$ position $\left(Y p \operatorname{LpxE} \_37^{\circ} \mathrm{C}\right)$. Another example included comparison of the relative intensities of product ions resulting from the competitive loss of acyl 
chains as either alkane carboxylic acids or alkyl ketenes. When the phosphate group was at the C-4' location $\left(Y p \operatorname{LpxE} 337^{\circ} \mathrm{C}\right)$ the ratio of the loss of an acyl chain as an alkyl ketene to that of an alkane carboxylic acid was much higher than the ratio of these competitive losses if the phosphate group was at the $\mathrm{C}-1$ position $\left(Y p L p x F \_37^{\circ} \mathrm{C}\right)$. It can therefore be concluded that the difference in structure for the $\mathrm{m} / \mathrm{z} 1324$ ion between $Y p L p x E \_37^{\circ} \mathrm{C}$ and $Y p L p x F \_37^{\circ} \mathrm{C}$ was the position of the phosphate group which means that the LpxE and LpxF phosphatase enzymes expressed in the mutant strains worked specifically.

\section{Determination of Ara4N Location in Monophosphoryl Tetra-Acylated Lipid A from YpLpxE_37 ${ }^{\circ} \mathrm{C}$ and $\mathrm{YpL} L x F \_37^{\circ} \mathrm{C}$}

The second most abundant ion in the $Y p \operatorname{LpxE} \_37^{\circ} \mathrm{C}$ and $Y p L p x F \_37^{\circ} \mathrm{C}$ mass spectra (Figure $1 \mathrm{~b}$ and $\mathrm{c}$ ), $\mathrm{m} / \mathrm{z}$ 1455 , corresponded to a monophosphoryl tetra-acylated lipid A structure with the addition of one Ara4N. The IRMPD $\mathrm{MS}^{2}$ tandem mass spectra of $m / z 1455$ ions for

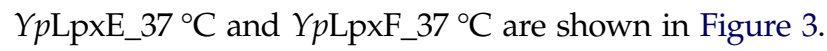
The most intense peak in both mass spectra was at $\mathrm{m} / \mathrm{z}$ 210, which was consistent with a fragment ion containing an Ara4N residue and a phosphate group ([Ara4N + $\left.\mathrm{PO}_{3}\right]^{-}$). This convincingly indicated the Ara4N was attached to the lipid $\mathrm{A}$ disaccharide backbone via a phosphodiester linkage in both $Y p L p x E \_37^{\circ} \mathrm{C}$ and $Y p L p x F \_37^{\circ} \mathrm{C}$ mass spectra. Figure 3 also shows several important differences between the two mass spectra. First, there was a series of A-type product ions with the addition of phosphate and Ara4N at $m / z 1170$ $\left({ }^{0,2} \mathrm{~A}_{2} 1 \mathrm{HPO}_{3} ; 1\right.$ Ara $\left.4 \mathrm{~N}\right), 883\left({ }^{0,4} \mathrm{~A}_{2} 1 \mathrm{HPO}_{3} ; 1\right.$ Ara $\left.4 \mathrm{~N}\right)$, and $639\left({ }^{0,4} \mathrm{~A}_{2}-\mathrm{C} 14(3-\mathrm{OH}) \_1 \mathrm{HPO}_{3} ; 1 \mathrm{Ara} 4 \mathrm{~N}\right)$ in the $Y p L p x E \_37^{\circ} \mathrm{C}$ mass spectrum (Figure $3 a$ ) and absent in the $Y p L p x F \_37^{\circ} \mathrm{C}$ mass spectrum (Figure $3 b$ ). Second, the only A-type product ions present in both $Y p$ LpxE_37 ${ }^{\circ} \mathrm{C}$ and $Y p L p x F \_37^{\circ} \mathrm{C}$ mass spectra were at $m / z 488\left({ }^{0,2} \mathrm{~A}_{2}-\mathrm{C} 14(3-\mathrm{OH})-\mathrm{C} 14(3-\mathrm{OH})\right.$ ket_0 $\mathrm{HPO}_{3} ; 0$ Ara $4 \mathrm{~N})$ and $m / z 428\left({ }^{0,4} \mathrm{~A}_{2}-\mathrm{C} 14(3-\mathrm{OH}) \_\quad \mathrm{HPO}_{3} ; 0\right.$ Ara4N); note that these ions did not contain phosphate or Ara4N. Further evidence for the different location of the phosphate and Ara $4 \mathrm{~N}$ in the precursor ion at $\mathrm{m} / \mathrm{z}$

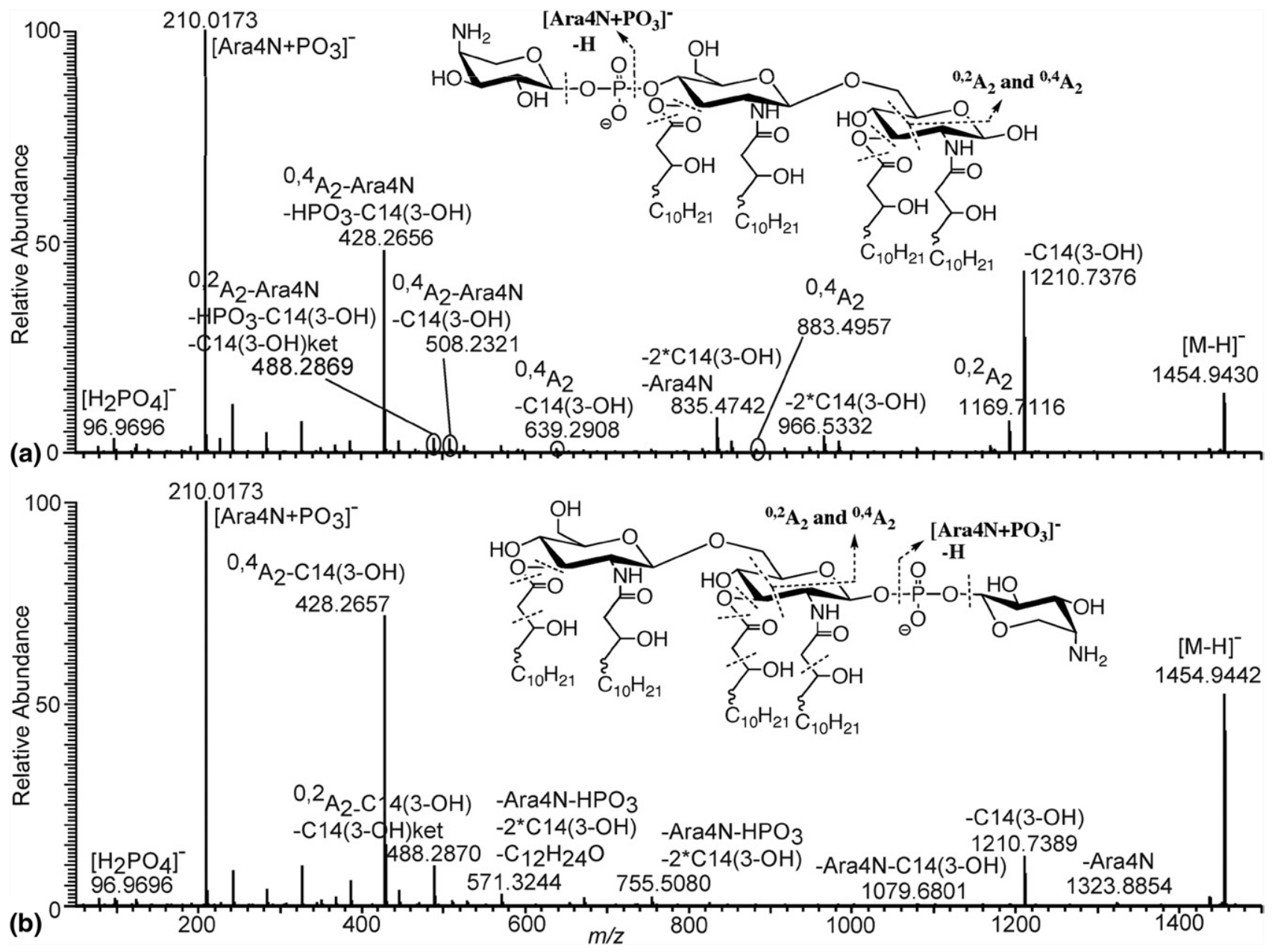

Figure 3. Negative ion mode ESI LTQ-FT IRMPD MS ${ }^{2}$ mass spectrum of the ion at $\mathrm{m} / \mathrm{z} 1455$ from (a) $Y p L p x E \_37^{\circ} \mathrm{C}$ and (b) $Y p L p x F \_37^{\circ} \mathrm{C}$. Inset structures show the proposed phosphate positioning and dashed lines indicate possible cleavage sites. 
1455 from $Y p$ LpxE_37 ${ }^{\circ} \mathrm{C}$ and $Y p L p x F \_37^{\circ} \mathrm{C}$ was seen in the CID MS $^{3}$ mass spectra for the ion at $\mathrm{m} / \mathrm{z} 1211$ derived from the $\mathrm{m} / \mathrm{z} 1455$ precursor by elimination of hydroxymyristic acid (SI Figure S3).

\section{Determination of the Phosphate Configuration in Diphosphoryl Tetra-Acylated Lipid A from

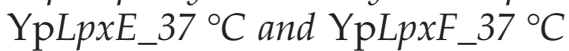

To determine the phosphorylation pattern and distinguish between pyrophosphate or bisphosphate forms in diphosphoryl tetra-acylated lipid A, we performed a series of tandem mass spectrometry experiments on the precursor ion at $\mathrm{m} / \mathrm{z} 1404$ isolated from both $Y p L p x E \_37^{\circ} \mathrm{C}$ and $Y p L p x F \_37^{\circ} \mathrm{C}$. The IRMPD $\mathrm{MS}^{2}$ tandem mass spectra of $m / z 1404$ ions for both

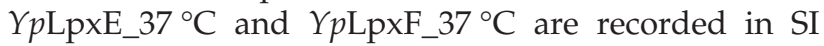
Figure $\mathrm{S} 4$. Both spectra show prominent fragment ions at $m / z 177$ and 159, which according to their accurate mass correspond to $\left[\mathrm{H}_{3} \mathrm{P}_{2} \mathrm{O}_{7}\right]^{-}$and $\left[\mathrm{HP}_{2} \mathrm{O}_{6}\right]^{-}$pyrophosphate product ions, respectively [29]. Although detection of pyrophosphate product ions strongly suggested the presence of a pyrophosphate group present in the precursor ion, the IRMPD tandem mass spectra of the $\mathrm{m} / \mathrm{z} 1404$ ion from $Y p \operatorname{LpxE} \_37^{\circ} \mathrm{C}$ and $Y p L p \times F \_37^{\circ} \mathrm{C}$ did not confirm the location of the pyrophosphate at either the C-1 or C $-4^{\prime}$ position, respectively. In other words, there were no distinguishing differences between the $Y p L p x E \_37^{\circ} \mathrm{C}$ and $Y p L p x F \_37^{\circ} \mathrm{C}$ IRMPD tandem mass spectra. At this stage, it was determined that an alternative dissociation method must be utilized to further ascertain the phosphorylation pattern of the ion at $\mathrm{m} / \mathrm{z}$ 1404. Instead of using IR photon-excitation, we employed the use of CID to fragment the precursor ion at $\mathrm{m} / \mathrm{z}$ 1404. However, the resulting CID $\mathrm{MS}^{2}$ mass spectra of the $\mathrm{m} / \mathrm{z} 1404$ ion did not result in any striking difference between $Y p L p x E \_37^{\circ} \mathrm{C}$ and $Y p \operatorname{LpxF} 37^{\circ} \mathrm{C}$ and therefore in no confirmation as to the pyrophosphate location.

Further multi-stage MS analyses were needed to help elucidate the structure for the ion at $\mathrm{m} / \mathrm{z} 1404$ from $Y p L p x E \_37^{\circ} \mathrm{C}$ and $Y p L p x F \_37^{\circ} \mathrm{C}$. One clear distinction was seen in the $\mathrm{MS}^{3}$ mass spectra of the ion at $\mathrm{m} / z 1160$ derived from the $m / z 1404$ precursor (Figure 4 ). The $m / z$ 1160 fragment ion resulted from elimination of a hydroxymyristic acid side chain from the $m / z 1404$ precursor ion. Several key differences in the tandem mass spectra between $Y p L p x E \_37^{\circ} \mathrm{C}$ and $Y p L p x F \_37^{\circ} \mathrm{C}$ highlighted the fact that the $\mathrm{m} / \mathrm{z} 1160$ ion from $Y p L p x E \_37^{\circ} \mathrm{C}$ had a different phosphate arrangement than that of the analogous ion from $Y p L p x F \_37^{\circ} \mathrm{C}$. The CID $\mathrm{MS}^{3}$ mass spectrum of the $\mathrm{m} / z 1160$ ion from $Y p L p x E \_37^{\circ} \mathrm{C}$ (Figure $4 \mathrm{a}$ ) displayed a series of A-type cross-ring product ions that retained one and two phosphate groups. The presence of these A-type product ions with two phosphate groups explicitly indicated that the C-4' position contained a pyrophosphate moiety. For example, fragment ions at $m / z$ 832, 648, and 588 corresponded to the following structures: ${ }^{0,4} \mathrm{~A}_{2}{ }_{2} 2 \mathrm{HPO}_{3}$, ${ }^{0,4} \mathrm{~A}_{2}-\mathrm{C}_{12} \mathrm{H}_{24} \mathrm{O} \_2 \mathrm{HPO}_{3}$, and ${ }^{0,4} \mathrm{~A}_{2}-\mathrm{C} 14(3-\mathrm{OH}) \_2 \mathrm{HPO}_{3}$. Additionally, an ion series corresponding to the loss of phosphate from the aforementioned fragment ions were also observed at $m / z 752\left({ }^{0,4} \mathrm{~A}_{2-} 1 \mathrm{HPO}_{3}\right), 568\left({ }^{0,4} \mathrm{~A}_{2-}\right.$ $\left.\mathrm{C}_{12} \mathrm{H}_{24} \mathrm{O} \_1 \mathrm{HPO}_{3}\right)$, and $508\left({ }^{0,4} \mathrm{~A}_{2}-\mathrm{C} 14(3-\mathrm{OH}) \_1 \mathrm{HPO}_{3}\right)$ further implicating the presence of phosphate at the $\mathrm{C}-4^{\prime}$ position in the $Y p \operatorname{LpxE} 337^{\circ} \mathrm{C}$ mass spectrum (Figure 4a).

In contrast, the $Y p L p x F \_37^{\circ} \mathrm{C}$ CID MS ${ }^{3}$ mass spectrum (Figure $4 \mathrm{~b}$ ) of the $m / z 1160$ fragment ion did not contain A-type product ions having one or two phosphate groups. A further distinction between the two tandem mass spectra followed from the comparison of the ratio of intensities for product ions arising from neutral loss of acyl chains as alkyl ketenes or alkane carboxylic acids. This was apparent in the ion series at $\mathrm{m} / \mathrm{z} 835$ and 817 . The $Y p \mathrm{LpxE} 337^{\circ} \mathrm{C}$ mass spectrum (Figure 4a) displayed a much more competitive loss of acyl chains as ketenes than the $Y p L p x F \_37^{\circ} \mathrm{C}$ mass spectrum (Figure $4 \mathrm{~b}$ ). For example, the intensity ratios of ions at $\mathrm{m} / \mathrm{z} 835: 817$ for $Y p L p x E \_37^{\circ} \mathrm{C}$ and $Y p L p x F \_37^{\circ} \mathrm{C}$ were $1: 1$ and $1: 2$, respectively. The presence of a pyrophosphate group at $\mathrm{C}-1$ in $Y p \mathrm{LpxF} 337^{\circ} \mathrm{C}$ was confirmed as follows. First, the $Y p L p x F \_37^{\circ} \mathrm{C}$ mass spectrum did not contain A-type product ions with phosphate groups. Second, the $Y p L p x F \_37^{\circ} \mathrm{C}$ mass spectrum contained several glycosidic fragment ions containing two phosphate groups at $m / z \quad 790\left(\mathrm{Y}_{1 \_} 2\right.$ $\left.\mathrm{HPO}_{3}\right), 772\left(\mathrm{Z}_{1} 2 \mathrm{HPO}_{3}\right), 546\left(\mathrm{Y}_{1}-\mathrm{C} 14(3-\mathrm{OH}) \_2 \mathrm{HPO}_{3}\right)$, and $528\left(\mathrm{Z}_{1}-\mathrm{C} 14(3-\mathrm{OH}) \_2 \mathrm{HPO}_{3}\right)$. It should be emphasized that these glycosidic fragment ions were also observed in the $Y p L p x E \_37^{\circ} \mathrm{C}$ mass spectrum. This was expected given the symmetrical nature of the lipid A structure represented by the $m / z 1404$ ion, in regard to cleavage of the glycosidic bond. In other words, distinction between a $\mathrm{C}$ or $\mathrm{B}$ ion from that of a $\mathrm{Y}$ or $\mathrm{Z}$ ion was not plausible without corroborating data (e.g., A-type product ions) given that both the $\mathrm{C}$ or $\mathrm{B}$ and $\mathrm{Y}$ or $\mathrm{Z}$ ion will be equivalent in mass and elemental composition.

Determination of Ara4N Location in Diphosphoryl Tetra-Acylated Lipid A from YpLpxE_37 ${ }^{\circ} \mathrm{C}$ and YpLpxF_37 ${ }^{\circ} \mathrm{C}$

The relative abundance of the precursor ion at $\mathrm{m} / \mathrm{z} 1535$, corresponding to a diphosphoryl tetra-acylated lipid A with one Ara4N modification, was considerably lower for both $Y p$ LpxE_37 ${ }^{\circ} \mathrm{C}$ and $Y p L p x F \_37^{\circ} \mathrm{C}$ mass spectra (Figure $1 \mathrm{~b}$ and $\mathrm{c}$ ) when compared to the $Y p \mathrm{WT} \_37^{\circ} \mathrm{C}$ mass spectrum (Figure 1a). The IRMPD tandem mass spectra for the $\mathrm{m} / \mathrm{z} 1535$ precursor ion from $Y p$ LpxE_37 ${ }^{\circ} \mathrm{C}$ and $Y p$ LpxF_37 ${ }^{\circ} \mathrm{C}$ (Figure 5) revealed several significant product ions. Both spectra contained an abundant fragment ion at $\mathrm{m} / \mathrm{z} 177$, which was pyrophosphate $\left(\left[\mathrm{H}_{3} \mathrm{P}_{2} \mathrm{O}_{7}\right]^{-}\right)$by accurate mass measurements. Additionally, two other low mass fragment ions worth noting were found at $m / z 210$ and 290 . These ions 


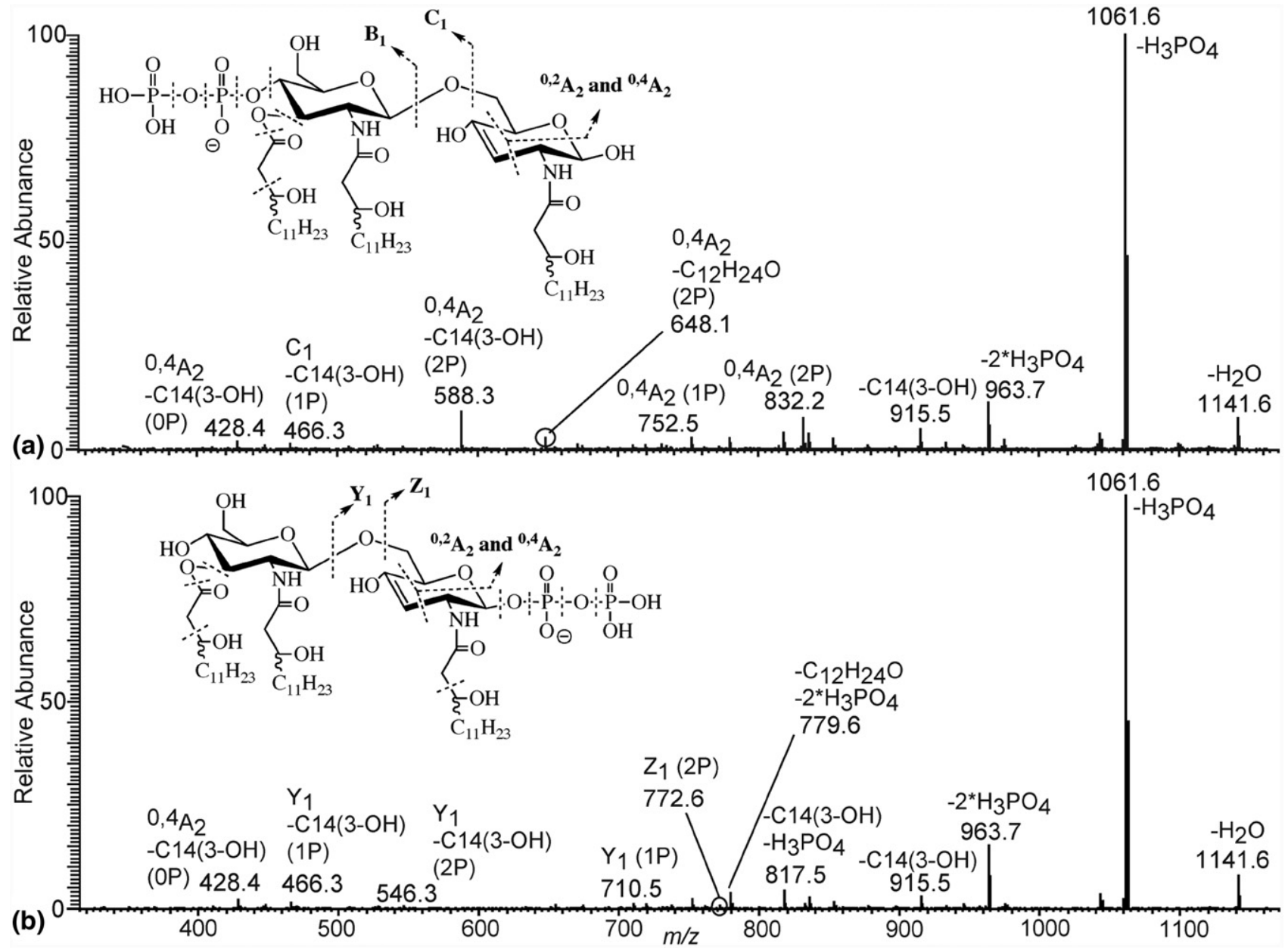

Figure 4. Negative ion mode ESI LTQ CID MS ${ }^{3}$ mass spectrum of the ion at $\mathrm{m} / \mathrm{z} 1160$ (from $\mathrm{m} / \mathrm{z} 1404$ ) from (a) $Y p$ LpxE_37 ${ }^{\circ} \mathrm{C}$ and (b) $Y p L p x F \_37^{\circ} \mathrm{C}$. Inset structures show proposed pyrophosphate positioning and dashed lines indicate possible cleavage sites.

corresponded to Ara $4 \mathrm{~N}$ plus phosphate, [Ara4N + $\left.\mathrm{PO}_{3}\right]^{-}$, and Ara4N plus two phosphates, [Ara4N + $\left.\mathrm{HP}_{2} \mathrm{O}_{6}\right]^{-}$, respectively. The elemental composition of the $\mathrm{m} / \mathrm{z} 210$ ion $\left(\mathrm{C}_{5} \mathrm{H}_{9} \mathrm{NO}_{6} \mathrm{P}\right)$ indicates it to be a cyclic phosphodiester species with $\mathrm{PO}_{3}^{-}$bound to $\mathrm{C}-1^{\prime}$ and C-2'. The fragment ion at $\mathrm{m} / \mathrm{z} 177$ suggested that a pyrophosphate was intrinsically present in the precursor ion structure. The fragment ions at $\mathrm{m} / \mathrm{z} 210$ and 290 indicated that the Ara4N was attached to the phosphate substituent and this phosphate substituent was pyrophosphate. This provided conclusive evidence that the phosphate and Ara4N configuration was a [pyrophosphate/Ara4N] in both YpLpxE_37 ${ }^{\circ} \mathrm{C}$ and Y $p$ LpxF_ $37^{\circ} \mathrm{C}$. The dominant primary dissociation of the $\mathrm{m} / \mathrm{z} 1535$ precursor ion involved neutral loss of Ara4N resulting in a fragment ion at $m / z 1404$. All other auxiliary dissociations resulted from a combination of neutral loss of Ara4N plus loss of phosphate and/or acyl chains.

Several product ions from the dissociation of the $\mathrm{m} / \mathrm{z}$ 1535 precursor were isolated and fragmented to ascertain the positioning of the phosphate substituents. The clearest indication as to the different phosphate position was seen in the $\mathrm{MS}^{3}$ mass spectra of the $\mathrm{m} / \mathrm{z} 1324$ fragment ion (by loss of [Ara $4 \mathrm{~N}+\mathrm{HPO}_{3}$ ] from the $\mathrm{m} / \mathrm{z}$ 1535 precursor) from $Y p \operatorname{LpxE} \_37^{\circ} \mathrm{C}$ and $Y p L p x F \_37^{\circ} \mathrm{C}$ (SI Figure S5). Although the $\mathrm{MS}^{3}$ mass spectra for $Y p L p x E \_37^{\circ} \mathrm{C}$ and $Y p \operatorname{LpxF} 377^{\circ} \mathrm{C}$ were similar, there were several key differences worth highlighting. The first of these was several A-type product ions containing a phosphate at $\mathrm{m} / \mathrm{z} 1020.5\left({ }^{0,2} \mathrm{~A}_{2}{ }_{1} \mathrm{HPO}_{3}-\mathrm{H}_{2} \mathrm{O}\right), 794.6$ $\left({ }^{0,2} \mathrm{~A}_{2}-\mathrm{C} 14(3-\mathrm{OH}) \mathrm{ket} \_1 \quad \mathrm{HPO}_{3}\right)$, and $508\left({ }^{0,4} \mathrm{~A}_{2}-\mathrm{C} 14(3-\right.$ $\mathrm{OH})_{1} 1 \mathrm{HPO}_{3}$ ) that were present in the $\mathrm{Y} p \mathrm{LpxE} \_37^{\circ} \mathrm{C}$ mass spectrum (SI Figure S5a) but not in the $Y p L p x F \_37^{\circ} \mathrm{C}$ mass spectrum (SI Figure S5b). Additionally, the competitive neutral loss of acyl chains as either alkane carboxylic acids or alkyl ketenes revealed the difference in phosphate location. This was demonstrated in the comparison of the ratio of product ions at $\mathrm{m} / \mathrm{z}$ 853:835, which was 1:1 in the $Y p \operatorname{LpxE} 37^{\circ} \mathrm{C}$ mass spectrum (SI Figure S5a) and 1:6 in the $Y p L p x F \_37^{\circ} \mathrm{C}$ mass spectrum (SI Figure S5b). The $Y p$ LpxE_ $37^{\circ} \mathrm{C}$ mass spectrum revealed a much more competitive loss of acyl chains as ketenes than the $Y p$ LpxF_ $37{ }^{\circ} \mathrm{C}$ mass spec- 
要
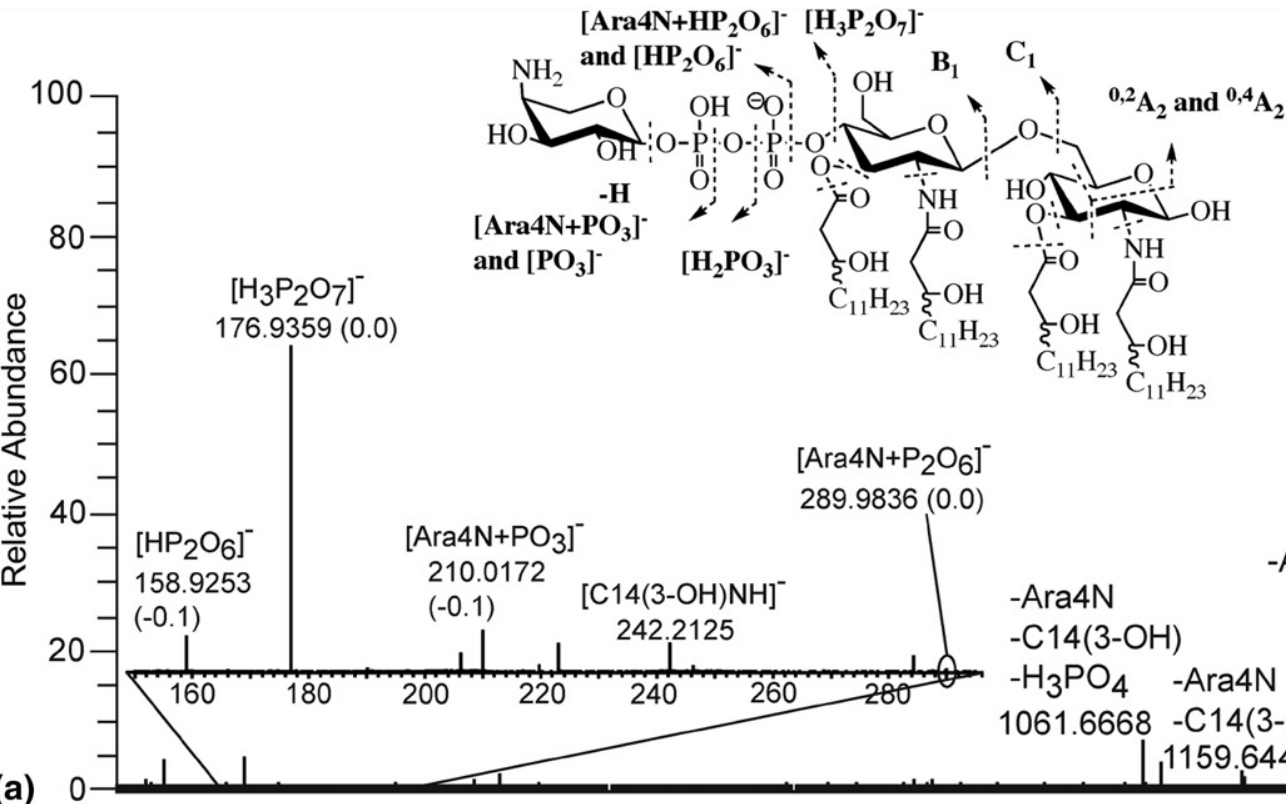

$[\mathrm{M}-\mathrm{H}]^{-}$

1534.0792

(a)

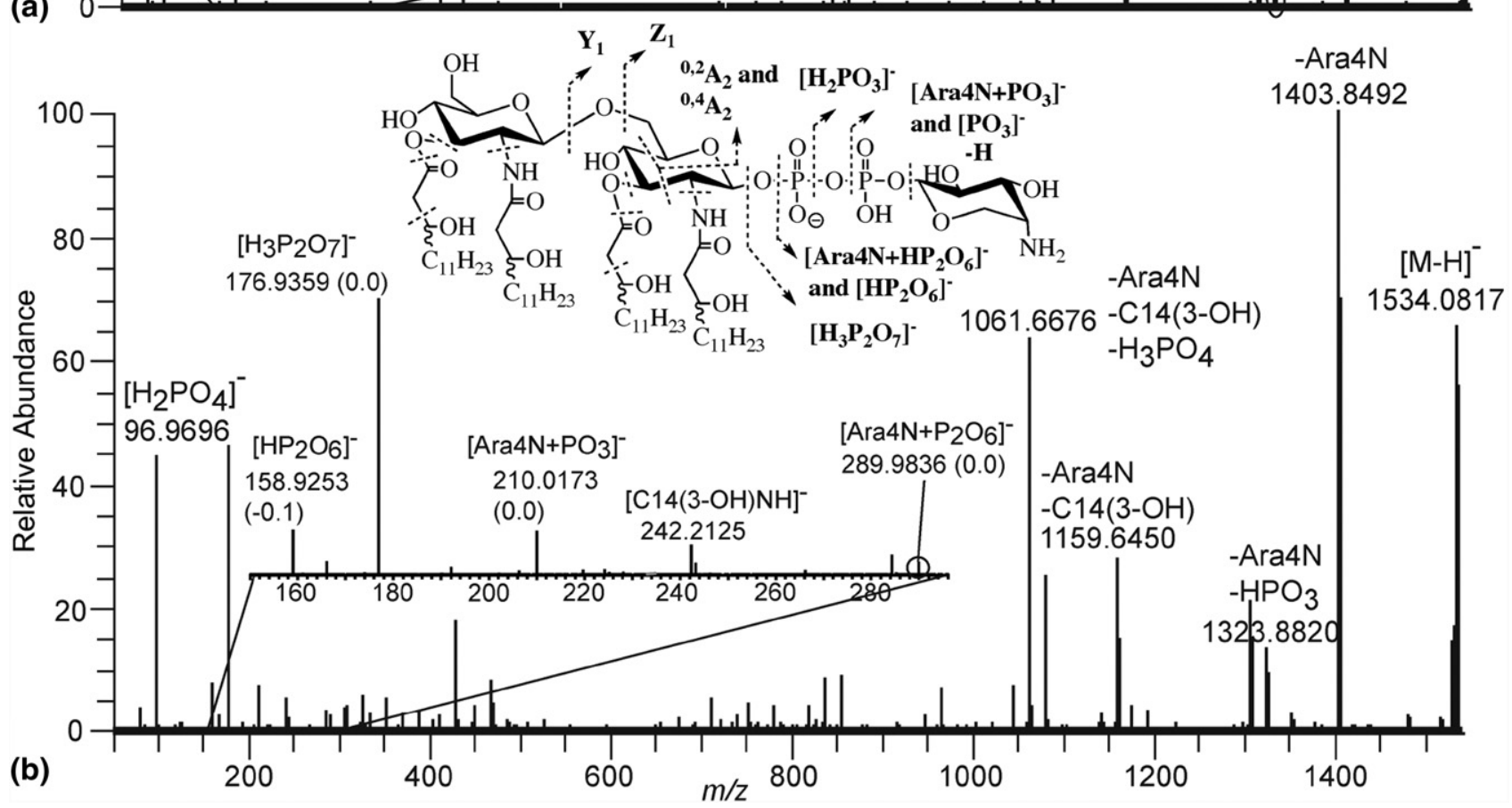

$\left[\mathrm{Ara} 4 \mathrm{~N}+\mathrm{P}_{2} \mathrm{O}_{6}\right]^{-}$

$289.9836(0.0)$
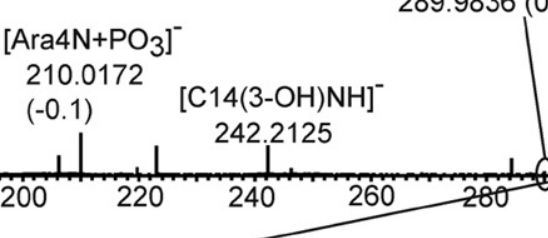

$-\mathrm{C} 14(3-\mathrm{OH})$

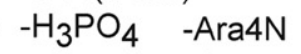

$1061.6668-\mathrm{C} 14(3-\mathrm{OH})$

$-\mathrm{Ara} \mathrm{N}-\mathrm{HPO}_{3}$

1323.8805
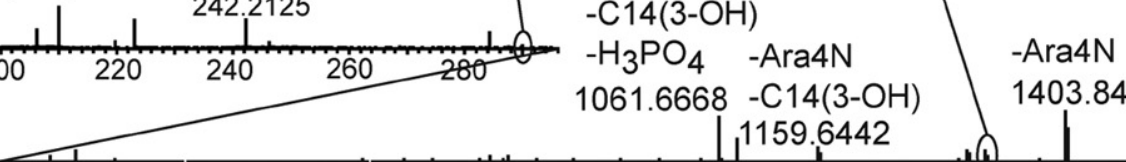

1403.8483

Figure 5. Negative ion mode ESI LTQ-FT IRMPD MS ${ }^{2}$ mass spectrum of the ion at $m / z 1535$ from (a) $Y p L p x E \_37^{\circ} \mathrm{C}$, and (b) $Y p L p x F \_37^{\circ} \mathrm{C}$. Inset mass spectra highlight the $\mathrm{m} / \mathrm{z} 150-300$ region. Inset structures show proposed pyrophosphate positioning and dashed lines indicate possible cleavage sites. Mass accuracy in mmu are in parenthesis for the following product ions: $\left[\mathrm{HP}_{2} \mathrm{O}_{6}\right]^{-},\left[\mathrm{H}_{3} \mathrm{P}_{2} \mathrm{O}_{7}\right]^{-}$, $\left[\text { Ara4 }+\mathrm{PO}_{3}\right]^{-}$, and $\left[\mathrm{Ara} 4 \mathrm{~N}+\mathrm{HP}_{2} \mathrm{O}_{6}\right]^{-}$.

trum. Finally, acyl chains lost as aldehyde eliminations were much more abundant in the $Y p L p x F \_37^{\circ} \mathrm{C}$ mass

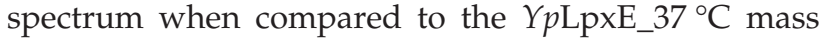
spectrum. This was seen in comparing the relative intensities of product ions at $\mathrm{m} / \mathrm{z} 1140$ (absent in YpLpxE_37 $\left.{ }^{\circ} \mathrm{C}\right), 895.6$, and 651.5. In summary, the $\mathrm{MS}^{n}$ data persuasively suggested that the ion at $\mathrm{m} / \mathrm{z} 1324$ (derived from the $\mathrm{m} / \mathrm{z} 1535$ precursor) contained a phosphate group at the C-4' for $Y p L p x E \_37{ }^{\circ} \mathrm{C}$ and at $\mathrm{C}-1$ for $Y p \operatorname{LpxF} 37^{\circ} \mathrm{C}$. Furthermore, collating the data analyses from Figures 5 and SI Figure S5 compellingly indicated that the precursor ion at $\mathrm{m} / z 1535$ contained an Ara4N-pyrophosphate moiety at C-4' for $Y p L p x E \_37^{\circ} \mathrm{C}$ and at $\mathrm{C}-1$ for $Y p L p x F \_37^{\circ} \mathrm{C}$.

Diphosphorylated lipid A can also be modified by the addition of two Ara4N moieties. This was clearly established in the $Y p W T \_37^{\circ} \mathrm{C}$ ESI LTQ-FT mass spectrum (Figure 1a), where the ion at $m / z 1666$ was consistent with a diphosphoryl tetra-acylated lipid A anion containing two Ara4N modifications. The IRMPD 
tandem mass spectrum of the $m / z 1666$ ion from $Y p W T \_37^{\circ} \mathrm{C}$ (SI Figure S6) displayed an abundant pyrophosphate anion at $\mathrm{m} / \mathrm{z} 177$ suggesting the presence of a pyrophosphate moiety in the precursor ion. Two other fragment ions of particular relevance were present at $\mathrm{m} / \mathrm{z} 210$ and 290 corresponding to [Ara4N + $\left.\mathrm{PO}_{3}\right]^{-}$and $\left[\mathrm{Ara} 4 \mathrm{~N}+\mathrm{HP}_{2} \mathrm{O}_{6}\right]^{-}$suggesting that at least one Ara4N was attached to the lipid A disaccharide backbone via a phosphate and pyrophosphate substituent. It should be pointed out that the precursor ion at $\mathrm{m} / \mathrm{z} 1666$ from $Y p W T \_37^{\circ} \mathrm{C}$ was a heterogeneous mixture of bisphosphate and pyrophosphate [29]. As with the bisphosphate structure, it was concluded that the two Ara $4 \mathrm{~N}$ modifications were located at the $\mathrm{C}-1$ phosphate and C-4' phosphate positions based on literature [24-28] and $\mathrm{MS}^{n}$ evidence (see above) suggesting that Ara4N was attached to the lipid A backbone via a phosphate linkage. Determination of the location for the two Ara4N modifications in the context of a pyrophosphorylated ion presented some challenging problems. The diphosphorylated lipid A precursor ion with two Ara4N modifications was present in extremely low

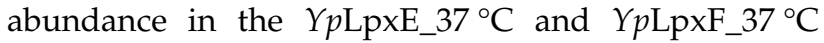
mass spectra (Figure $1 \mathrm{~b}$ and $c$ ) and this severely hindered our efforts in performing multi-stage tandem MS experiments with the $m / z 1666$ ion, such that we were unable to ascertain the configuration of the pyrophosphorylated lipid A precursor ion that had two Ara4N modifications.

\section{Determination of Phosphate Location in Monophosphoryl Penta-Acylated_C12 Lipid A from YpLpxE_37 ${ }^{\circ} \mathrm{C}$ and $\mathrm{Yp} L p x F \_37^{\circ} \mathrm{C}$}

In addition to ions corresponding to tetra-acylated lipid A structures in $Y p L p x E \_37^{\circ} \mathrm{C}$ and $Y p L p x F \_37^{\circ} \mathrm{C}$, there were also ions whose $m / z$ pointed to penta-acylated_C12 lipid A structures. The ion at $m / z 1506$ (Figure 1) was consistent with a monophosphoryl penta-acylated_C12 lipid A structure. Multi-stage tandem MS analyses of the precursor ion at $m / z 1506$ demonstrated the overall activity of the phosphatase enzymes, LpxE and LpxF, in regard to monophosphoryl penta-acylated_C12 lipid A. $\mathrm{MS}^{n}$ analyses involving $\mathrm{MS}^{2}$ IRMPD tandem mass spectra (SI Figure S7) and $\mathrm{MS}^{n}$ CID tandem mass spectra (SI Figure S8-S10) of the precursor ion at $\mathrm{m} / \mathrm{z}$ 1506 confirmed the positioning of the C12:0 secondary fatty acid and established phosphate location in pentaacylated $Y p L p x E \_37^{\circ} \mathrm{C}$ and $Y p L p x F \_37^{\circ} \mathrm{C}$. The phosphorylation pattern was determined by comparing dissociation mass spectra from $Y p L p x E \_37^{\circ} \mathrm{C}$ and $Y p L p x F \_37^{\circ} \mathrm{C}$ and identifying diagnostic product ions indicating phosphate positioning in the same manner as outlined for tetra-acylated lipid A anions (vide supra). It was determined that the monophosphoryl pentaacylated_C12 lipid A ion at $m / z 1506$ from $Y p$ LpxE_37 ${ }^{\circ} \mathrm{C}$ contained the phosphate group at the $C-4^{\prime}$ position.
Conversely, the ion at $m / z 1506$ from $Y p L p x F \_37^{\circ} \mathrm{C}$ had its monophosphate situated at either C-1 or C-4'.

These data indicated that the C-1-specific phosphatase (LpxE) displayed high selectivity in removing the C-1 phosphate group from monophosphoryl pentaacylated_C12 lipid A. Conversely, the C-4'-specific phosphatase (LpxF) showed decreased activity for removing the C-4' phosphate group when the lipid A structure contained a secondary fatty acid at the C-3' position. This observation was in agreement with a previous report describing decreased activity of Francisella LpxF to dephosphorylated lipid A at the C-4' position when the lipid A structure contained a secondary acyl chain at the C-3' position [32]. It was speculated that the secondary acyl chain at the $\mathrm{C}-3^{\prime}$ position sterically hindered the activity of the LpxF enzyme, thereby not allowing complete removal of the C-4' phosphate group. An alternative explanation for decreased activity of LpxF in penta-acylated_C12 lipid A from $Y p$ is that LpxF is not native to $Y p$ and introduction of this enzyme into $Y p$ could have unknown consequences, suggesting that a simple steric explanation for lack of activity might be too simplistic. Furthermore, given the high specificity of enzymes not only to their specific function but also to their native environment (e.g., Francisella versus Yersinia), the fact that these non-native phosphatase enzymes work so efficiently in Yersinia was surprising and not easily explainable.

\section{Multi-Stage Tandem MS Analyses of Other Penta-Acylated_C12 Lipid A Precursor Ions from YpLpxE_37 ${ }^{\circ} \mathrm{C}$ and $\mathrm{YpL} L x F \_37^{\circ} \mathrm{C}$}

Precursor ions at $m / z 1586$ (diphosphoryl), 1637 (monophosphoryl with 1 Ara4N), 1717 (diphosphoryl with 1 Ara4N), and 1848 (diphosphoryl with 2 Ara4N) were identified in Figure 1 and all corresponded by mass to penta-acylated_C12 lipid A structures. Here, as was the case for the ion at $m / z$ 1506, the fifth acyl group was C12:0 and positioned as a secondary fatty acid on the C-3' acyl chain via an ester linkage at the 3-hydroxyl position. The C-1 position phosphatase, LpxE, resulted in efficient removal of the phosphate group at the C-1 position for all penta-acylated_C12 lipid A structures and therefore it was possible to determine the location of phosphate and Ara4N for precursor ions at $m / z$ 1586, 1637 , and 1717 in $Y p$ LpxE_37 ${ }^{\circ} \mathrm{C}$. It should be noted that because of the relative low abundance of the precursor

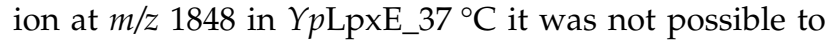
fully interrogate this ion and thus the structure was left ambiguous. Following $\mathrm{MS}^{2}$ analysis of the precursor ion at $m / z 1586$ from $Y p$ LpxE_37 ${ }^{\circ} \mathrm{C}$ (SI Figure S11a), it was determined that the diphosphorylation pattern in this particular precursor ion was in fact a pyrophosphate located at the C-4' position (analogous to the ion at $\mathrm{m} / \mathrm{z}$ 1404 from $\left.Y p L p x E \_37^{\circ} \mathrm{C}\right)$. Next, the precursor ion at $\mathrm{m} / z 1637$ from $Y p L p x E \_37^{\circ} \mathrm{C}$ was determined to have a C-4' phosphate with an Ara4N substituent attached to 
the lipid A backbone via the C-4' phosphate group (SI Figure S12a; analogous to the ion at $m / z 1455$ in $\left.Y p L p x E \_37^{\circ} \mathrm{C}\right)$. The phosphate and Ara4N configuration for the precursor ion at $\mathrm{m} / \mathrm{z} 1717$ was determined to be Ara4N attachment to pyrophosphate at the C-4' position (SI Figure S13a; analogous to the ion at $\mathrm{m} / \mathrm{z}$ 1535 for LpxE_37 ${ }^{\circ} \mathrm{C}$ ).

Phosphate and Ara4N location for the precursor ions at $m / z 1586$ (SI Figure S11b), 1637 (SI Figure S12b), 1717 (SI Figure S13b), and 1848 (no mass spectrum due to low abundance) from $Y p L p x F \_37^{\circ} \mathrm{C}$ was not manageable due to the inefficiency of the C-4' phosphatase, LpxF, to remove the C-4' phosphate group from pentaacylated_C12 lipid A when the fifth fatty acid is attached via an acyloxyacyl linkage to the C-3' primary acyl chain. Without efficient removal of the C-4' phosphate group, the precursor ion at $m / z 1637$ was a heterogeneous mixture of $\mathrm{C}-1$ and $\mathrm{C}-4^{\prime}$ monophosphate and the precursor ions at $m / z$ 1586, 1717, and 1848 were a heterogeneous mixture of bisphosphate and pyrophosphate. A heterogeneous mixture of phosphorylation patterns convolutes the dissociation spectra to a point that specific structure determination is not likely.

\section{Approximate Quantification of Bisphosphate and Pyrophosphate Forms}

As evident from the Figure 1 data, both LpxE and LpxF efficiently removed one phosphate group from diphosphoryl tetra-acylated lipid A extracted from $Y p$. The dominant peak in both $Y p$ LpxE_37 ${ }^{\circ} \mathrm{C}$ (Figure $1 \mathrm{~b}$ ) and $Y p L p x F \_37^{\circ} \mathrm{C}$ (Figure 1c) is at $\mathrm{m} / \mathrm{z} 1324$ corresponding to monophosphoryl tetra-acylated lipid A. This indicated that the dominant form of the diphosphorylated $Y p W T \_37^{\circ} \mathrm{C}$ is bisphosphate. Previous estimates of the amount of bisphosphate versus pyrophosphate from lipid A extracted from $Y p$ were unattainable using $Y p W T \_37^{\circ} \mathrm{C}$ only (Figure 1a) [29]. Incorporation of LpxE and LpxF effectively eliminated bisphosphoryl

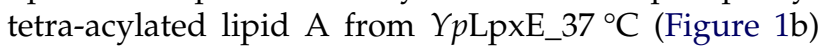
and $Y p L p x F \_37^{\circ} \mathrm{C}$ (Figure 1c). This allowed us to estimate the amount of pyrophosphate present in tetraacylated lipid A from $Y p L p x E \_37^{\circ} \mathrm{C}$ and $Y p L p x F \_37^{\circ} \mathrm{C}$ on the basis of relative intensities from $\mathrm{MS}^{1}$ mass spectra. Our estimation of relative percentages of pyrophosphate is not devoid of several major assumptions, as the use of precursor ion relative abundance to quantitatively determine components of a mixture is problematic for several reasons [37, 38]. Most importantly, electrospray ionization efficiencies vary between structures, making their absolute abundances difficult to determine.

Our next assumption, supported by comprehensive tandem mass spectrometric analyses of $Y p L p x E \_37^{\circ} \mathrm{C}$ and $Y p L p x F \_37^{\circ} \mathrm{C}$, was that LpxE and LpxF acted at near $100 \%$ efficiency and specificity for tetra-acylated lipid A. In other words, we assumed that all diphosphoryl tetra-acylated lipid A present in $Y p L p x E \_37^{\circ} \mathrm{C}$ (Figure $1 b$ ) and $Y p L p x F \_37^{\circ} \mathrm{C}$ (Figure 1c) is C-4' position pyrophosphate and $\mathrm{C}-1$ position pyrophosphate, respectively. Given these assumptions, we determined the relative percentage of pyrophosphate (ESI LTQ-FT mass spectra $(n=3))$ present in tetra-acylated lipid A from $Y p$ LpxE_37 ${ }^{\circ} \mathrm{C}$ to be $2 \% \pm 0.1 \%$ (monophosphoryl $98 \% \pm 0.1 \%$ ) and the relative percentage of pyrophosphate present in tetra-acylated lipid A from $Y p$ LpxF_37 ${ }^{\circ} \mathrm{C}$ to be $9 \% \pm 0.5 \%$ (monophosphoryl was $91 \% \pm 0.5 \%$ ). These percentage values were calculated by summing the relative intensities for all peaks whose $\mathrm{m} / \mathrm{z}$ values were associated with tetra-acylated monophosphorylated and pyrophosphorylated lipid A structures. The $m / z$ values used for monophosphoryl were 1324 and 1455 . The $m / z$ values used for pyrophosphoryl were 1404, 1535, and 1666. Next, monophosphoryl percentage was calculated by taking the sum of monophosphoryl intensities divided by the total intensities of (monophosphoryl + pyrophosphoryl). Pyrophosphoryl percentage was calculated by taking the sum of pyrophosphoryl intensities divided by the total intensities of (monophosphoryl + pyrophosphoryl).

Extrapolation of this data to include an estimate of the relative amount of pyrophosphate present in tetraacylated lipid A extracted from $Y p W T \_37^{\circ} \mathrm{C}$ is further complicated because more assumptions must be made. For example, one way to estimate the amount of pyrophosphate in $Y p W T \_37^{\circ} \mathrm{C}$ is to assume all lipid A from $Y p W T \_37^{\circ} \mathrm{C}$ is represented in both $Y p L p x E \_37^{\circ} \mathrm{C}$ and $Y p \operatorname{LpxF} 377^{\circ} \mathrm{C}$ in equal proportions as seen in the following equation:

$$
\begin{aligned}
& \text { YpWT_37 }{ }^{\circ} \mathrm{C} \text { (lipid A) }
\end{aligned}
$$

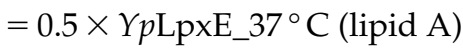

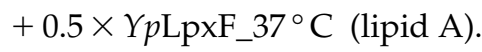

Next, we can insert the percentages of pyrophosphate seen in $Y p L p x E \_37^{\circ} \mathrm{C}$ and $\mathrm{YpLpxF} 337^{\circ} \mathrm{C}$ as follows:

$$
\begin{aligned}
0.5 & \times(2 \%)+0.5 \times(9 \%) \\
& =Y p W T \_37^{\circ} \mathrm{C} \text { pyrophosphate }
\end{aligned}
$$

Based on this rationale, tetra-acylated lipid A from Y pWT_37 ${ }^{\circ} \mathrm{C}$ would contain ca. 5-6\% pyrophosphate. It is difficult to estimate the error associated with the 5-6\% pyrophosphate in $Y p W T \_37^{\circ} \mathrm{C}$ and the figure must be considered tentative. Although crude, this is the first attempt to assign a relative amount of pyrophosphate in $Y p \mathrm{WT} \_37^{\circ} \mathrm{C}$ since this form was discovered [29]. 


\section{Discussion}

\section{Distinction of Bisphosphate and Pyrophosphate} Forms

To determine the phosphorylation pattern in lipid A extracted from $Y p$ grown at $37^{\circ} \mathrm{C}$, we incorporated specific lipid A phosphatase enzymes, LpxE and LpxF, into the $Y p$ KIM6+ strain followed by tandem mass spectrometry. This molecular biology approach coupled to tandem mass spectrometry was utilized to reduce the inherent heterogeneity observed in $Y p W T \_37^{\circ} \mathrm{C}$ lipid A phosphorylation. The inherent heterogeneity is caused by the presence of both bisphosphate and pyrophosphate forms of diphosphorylated lipid A from YpWT_37 ${ }^{\circ} \mathrm{C}$ [29]. Structural characterization of diphosphorylated lipid A from $Y p W T \_37^{\circ} \mathrm{C}$ via tandem MS did not result in specific localization of pyrophosphate or Ara4N. However, tandem mass spectrometric anal-

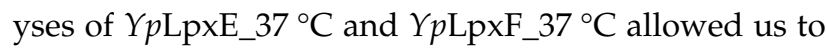
verify the specificity and efficiency of LpxE and LpxF and also provided unambiguous tandem mass spectra detailing the presence and location of pyrophosphate and confirmed Ara4N attachment sites in lipid A extracted from $Y p$.

Scheme 1 summarizes tetra-acylated lipid A structures from $Y p$ LpxE_37 ${ }^{\circ} \mathrm{C}$ (Figure $1 \mathrm{~b}$ and SI Table S2) and $Y p L p x F \_37^{\circ} \mathrm{C}$ (Figure 1c and SI Table S3) with the corresponding $m / z$ values. Of particular interest, diphosphoryl tetra-acylated lipid A from $Y p$ contains a pyrophosphate substituent at both the C-1 and C-4' positions. Moreover, Scheme 1 illustrates that these pyrophosphate substituents can be modified with Ara4N. Scheme 2 summarizes the structures of pentaacylated_C12 lipid A variants including those in which the C-4' position pyrophosphate was also identified. However, we were unable to confirm C-1 position

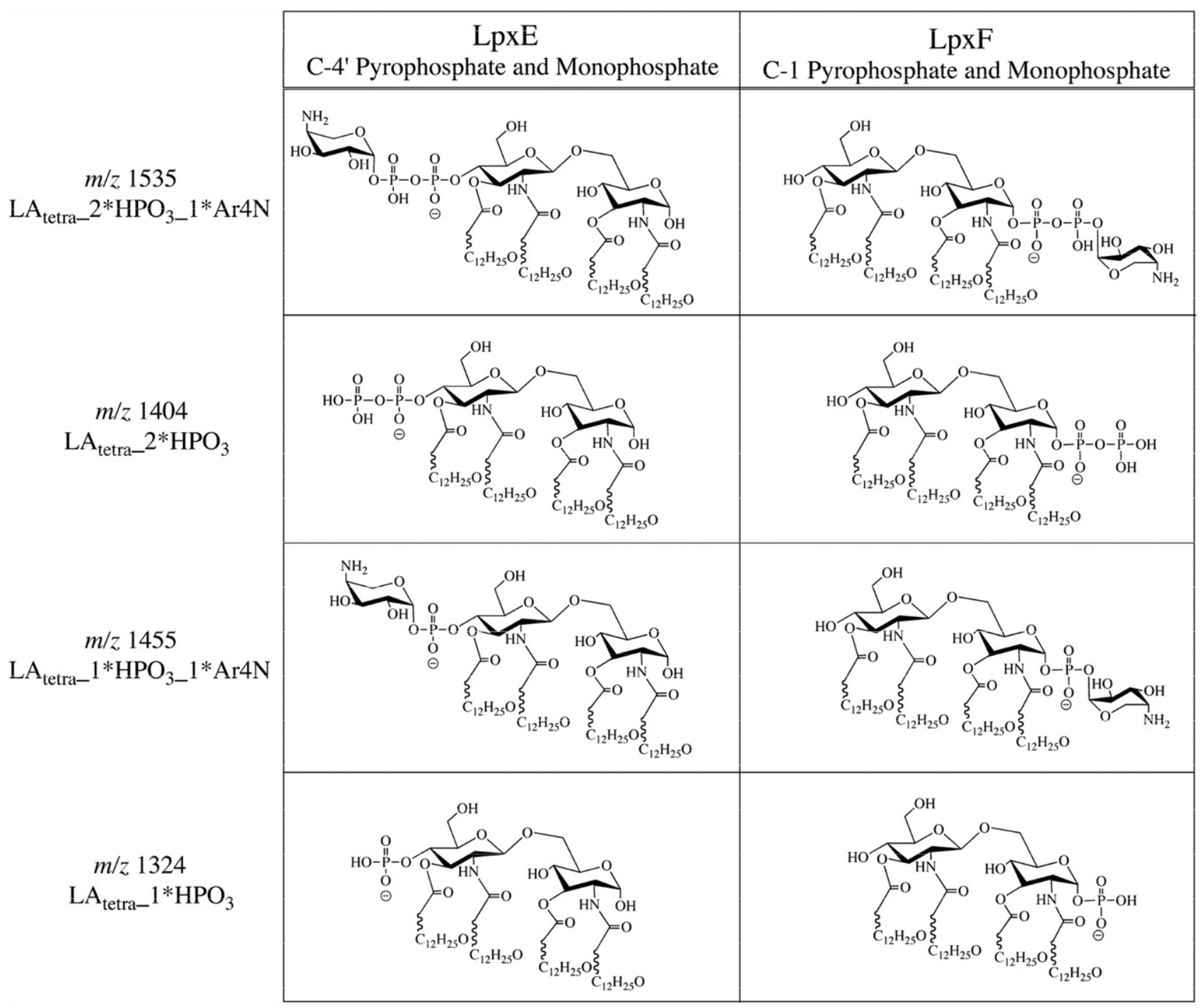

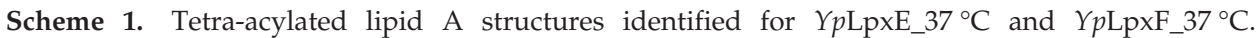
In $Y p$ LpxE_ $37^{\circ} \mathrm{C}$, monophosphate, pyrophosphate, and Ara4N are located at the C-4' position. In Y p L pxF_3 $37^{\circ} \mathrm{C}$, monophosphate, pyrophosphate, and Ara4N are located at the $\mathrm{C}-1$ position. 


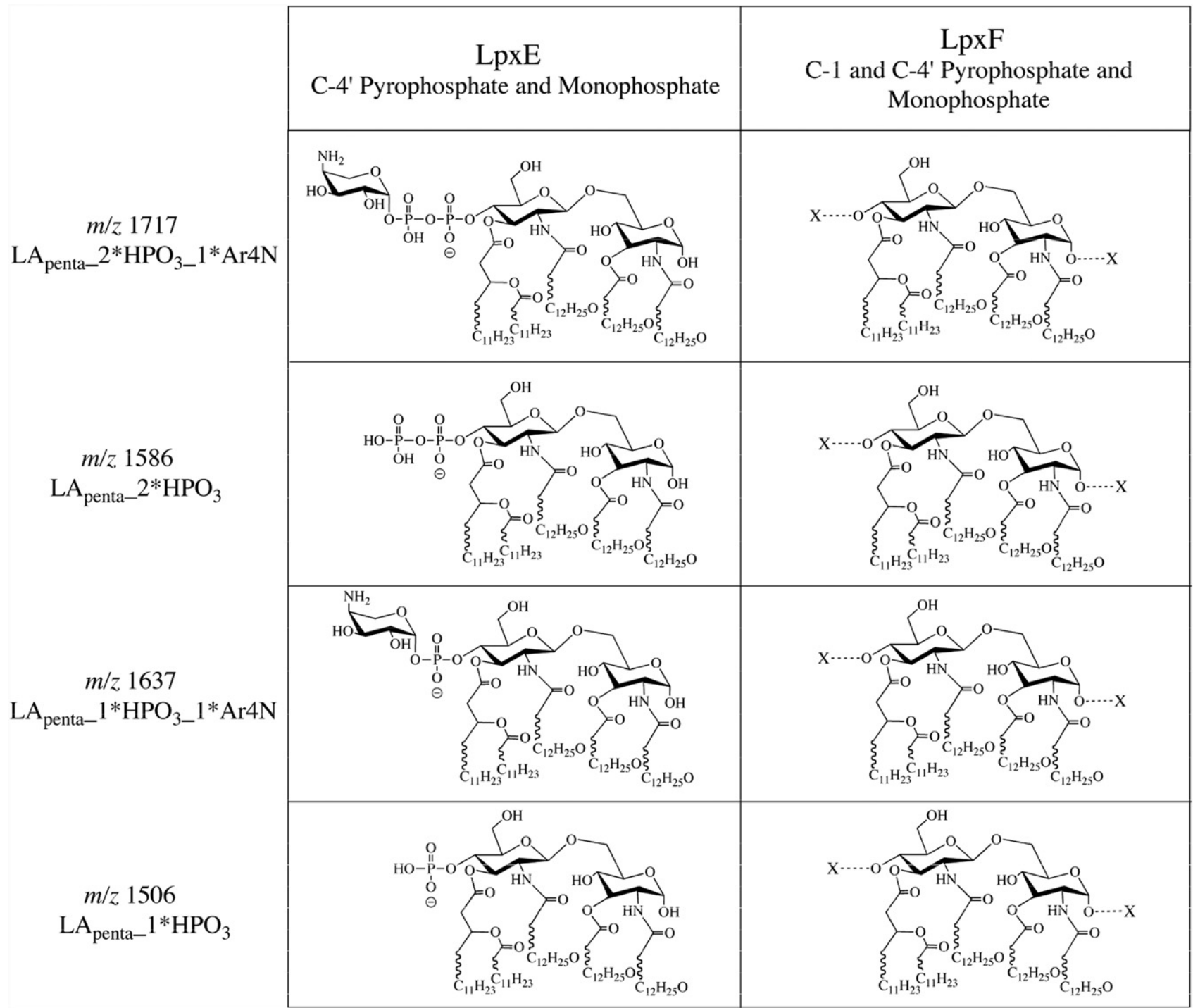

Scheme 2. Penta-acylated_C12 lipid A structures identified for $Y p \operatorname{LpxE} 37^{\circ} \mathrm{C}$ and $Y p L p x F \_37^{\circ} \mathrm{C}$. In $Y p L p x E \_37^{\circ} \mathrm{C}$, monophosphate, pyrophosphate, and Ara4N are located at the C-4' position. In $Y p L p x F \_37^{\circ} \mathrm{C}$, monophosphate, pyrophosphate, and Ara4N are located at the $\mathrm{C}-1$ and $\mathrm{C}-4^{\prime}$ positions. For Y $p$ LpxF_37 ${ }^{\circ} \mathrm{C}, \mathrm{X}$ represents bisphosphate and pyrophosphate for diphosphoryl lipid A (ions at $\mathrm{m} / \mathrm{z} 1717$ and 1586). For monophosphoryl lipid A (ions at $\mathrm{m} / \mathrm{z} 1637$ and 1506) X represents monophosphate attachment at either $\mathrm{C}-1$ or $\mathrm{C}-4^{\prime}$ positions.

pyrophosphate in penta-acylated_C12 lipid A due to the lack of LpxF activity in lipid A structures containing a secondary fatty acid at the C-3' position. It has been suggested in literature that other gram-negative organisms, such as Helicobacter pylori and Leptospira interrogans, process a C- $4^{\prime}$ phosphatase that can dephosphorylate the C-4' position in the presence of a secondary acyl chain at the C-3' position [32]. To date, we have not investigated the use of other C- $4^{\prime}$ phosphatases.

The importance of defining the structure of $Y p$ lipid A relates to how it corresponds to its biological function. Of particular relevance, specific phosphorylation patterns of lipid A structure are known to greatly influence LPS's pro-inflammatory capabilities. This observation is not without precedent, as lipid A phosphate groups are known to foster ionic interactions crucial for LPS binding to the TLR4-MD-2 complex [11]. Subsequently, lipid A phosphate plays a critical role in LPS bioactivity and full activation of the TLR4 signaling pathway $[15,16]$. A number of pathogenic organisms displaying reduced pro-inflammatory activities synthesize non-phosphorylated or monophosphorylated lipid A structures [39-52]. The phospho-deficient aspects of these lipid A structures have been linked to reduced endotoxic properties and diminished affinity towards host cationic antimicrobial peptides. Lipid A structures that moderate their endotoxic properties but still maintain some immunostimulatory qualities could potentially be used as vaccine adjuvants [53-56]. 
At this stage, the significance of pyrophosphorylated lipid A is yet to be established. Ongoing investigations will provide insight into the role that pyrophosphorylated lipid A plays in the relationship between the pathogen and host. One hypothesis is that pyrophosphorylation reduces the net ionic charge of the lipid A structure compared to biphosphorylation due to coulombic repulsion. A reduction in net ionic charge could bias the pathogen's chance of host detection by modulating its LPS pro-inflammatory response, as seen in bacteria that synthesize monophosphorylated lipid A. Alternatively, pyrophosphorylated lipid A could potentially serve an unknown biological role pertinent to bacterial survival but not necessarily related to pathogenesis (e.g., outer membrane structural integrity). In either case, the establishment of pyrophosphorylated lipid A in $Y p$ provides a step for further expounding the function and role of lipid A phosphorylation.

\section{Conclusions}

The presence of pyrophosphate in lipid A extracted from $Y p$ grown at $37^{\circ} \mathrm{C}$ has been confirmed by the use of specific lipid A phosphatase enzymes followed by multi-stage tandem mass spectrometry. Moreover, localization of pyrophosphate to both the C-1 and C-4' positions in tetra-acylated lipid A from $Y p$ was demonstrated. It was therefore concluded that diphosphoryl tetra-acylated lipid A extracted from $Y p$ was a heterogeneous mixture of C-1 and C-4' bisphosphate, C-1 pyrophosphate, and C-4' pyrophosphate. Additionally, it was established that Ara4 $\mathrm{N}$ was exclusively attached to the lipid A disaccharide backbone via a phosphate linkage. This phosphate linkage was found to be either monophosphate or pyrophosphate.

\section{Acknowledgments}

The authors thank the NIAID (1U54 AI57141) and NIEHS (5P30ES007033-10) for funding and support. Additional thanks are due to the Mass Spectrometry Facilities, located at the University of Washington School of Pharmacy, and the Proteomics Resource of the University of Washington School of Medicine (UWPR95794).

\section{Appendix A Supplementary Material}

Supplementary material associated with this article may be found in the online version at doi:10.1016/ j.jasms.2010.01.008.

\section{References}

1. Trent, M. S.; Stead, C. M.; Tran, A. X.; Hankins, J. V. Diversity of Endotoxin and Its Impact on Pathogenesis. J. Endotox. Res. 2006, 12, 205-223.

2. Beutler, B.; Rietschel, E. T. Innate Immune Sensing and Its Roots: The Story of Endotoxin. Nat. Rev. Immunol. 2003, 3, 169-176.

3. Gioannini, T. L.; Weiss, J. P. Regulation of Interactions of GramNegative Bacterial Endotoxins with Mammalian Cells. Immunol. Res. 2007, 39, 249-260.
4. Aderem, A.; Ulevitch, R. J. Toll-Like Receptors in the Induction of the Innate Immune Response. Nature 2000, 406, 782-787.

5. Hoshino, K.; Takeuchi, O.; Kawai, T.; Sanjo, H.; Ogawa, T.; Takeda, Y.; Takeda, K.; Akira, S. Toll-Like Receptor 4 (TLR-4)-Deficient Mice are Hyporesponsive to Lipopolysaccharide: Evidence for TLR4 as the lps Gene Product. J. Immunol. 1999, 162, 3749-3752.

6. Shimazu, R.; Akashi, S.; Ogata, H.; Nagai, Y.; Fukudome, K.; Miyake, K. Kimoto, M. MD-2, a Molecule that Confers Lipopolysaccharide Responsiveness on Toll-Like Receptor 4. J. Exp. Med. 1999, 189, 1777-1782.

7. Medzhitov, R.; Preston-Hurlburt, P.; Janeway, C. A. Jr. A Human Homologue of the Drosophila Toll Protein Signals Activation of Adaptive Immunity. Nature 1997, 388, 394-397.

8. Tobias, P. S.; Soldau, K.; Ulevitch, R. J. Isolation of a LipopolysaccharideBinding Acute Phase Reactant from Rabbit Serum. J. Exp. Med. 1986, 164, 777-793.

9. Ulevitch, R. J.; Tobias, P. S. Recognition of Gram-Negative Bacteria and Endotoxin by the Innate Immune System. Curr. Opin. Immunol. 1999, 11, 19-22.

10. Miyake, K. Roles for Accessory Molecules in Microbial Recognition by Toll-Like Receptors. J. Endotoxin Res. 2006, 12, 195-204.

11. Park, B. S.; Song, D. H.; Kim, H. M.; Choi, B. S.; Lee, H.; Lee, J. O. The Structural Basis of Lipopolysaccharide Recognition by the TLR4-MD-2 complex. Nature 2009, 458, 1191-1195.

12. Raetz, C. R.; Whitfield, C. Lipopolysaccharide Endotoxins. Annu. Rev. Biochem. 2002, 71, 635-700.

13. Miller, S. I.; Ernst, R. K.; Bader, M. W. LPS, TLR4, and Infectious Disease Diversity. Nat. Rev. Microbiol. 2005, 3, 36-46.

14. Golenbock, D. T.; Hampton, R. Y.; Qureshi, N.; Takayama, K.; Raetz, C. R. H. Lipid A-Like Molecules that Antagonize the Effects of Endotoxins on Human Monocytes. J. Biol. Chem. 1991, 266, 19490-19498.

15. Loppnow, H.; Brade, H.; Durrbaum, I.; Dinarello, C. A.; Kusumoto, S.; Rietschel, E. T.; Flad, H. D. IL-1 Induction-Capacity of Defined Lipopolysaccharide Partial Structures. J. Immunol. 1989, 142, 3229-3238.

16. Rietschel, E. T.; Kirikae, T.; Schade, F. U.; Mamat, U.; Schmidt, G. Loppnow, H.; Ulmer, A. J.; Zahringer, U.; Seydel U.; Dipadova, F.; Schreier, M.; Brade, H. Bacterial Endotoxin: Molecular Relationship of Structure to Activity and Function. FASEB J. 1994, 8, 217-225.

17. Baldridge, J. R.; McGowan, P.; Evans, J. T.; Cluff, C.; Mossman, S. Johnson, D.; Persing, D. Taking a Toll on Human Disease: Toll-Like Receptor 4 Agonists as Vaccine Adjuvants and Monotherapeutic Agents. Expert Opin. Biol. Ther. 2004, 4, 1129-1138.

18. Gunn, J. S.; Lim, K. B.; Krueger, J.; Kim, K.; Guo, L.; Hackett, M.; Miller, S. I. PmrA-PmrB-Regulated Genes Necessary for 4-Aminoarabinose Lipid A Modification and Polymyxin Resistance. Mol. Microbiol. 1998 27, 1171-1182.

19. McCoy, A. J.; Liu, H.; Falla, T. J.; Gunn, J. S. Identification of Proteus mirabilis Mutants with Increased Sensitivity to Antimicrobial Peptides. Antimicrob. Agents Chemother. 2001, 45, 2030-2037.

20. Moskowitz, S. M.; Ernst, R. K.; Miller, S. I. PmrAB, a Two-Component Regulatory System of Pseudomonas aeruginosa that Modulates Resistance to Cationic Antimicrobial Peptides and Addition of Aminoarabinose to Lipid A. J. Bacteriol. 2004, 186, 575-579.

21. Gunn, J. S.; Ryan, S. S.; Van Velkinburgh, J. C.; Ernst, R. K.; Miller, S. I Genetic and Functional Analysis of a PmrA-PmrB-Regulated Locus Necessary for Lipopolysaccharide Modification, Antimicrobial Peptide Resistance, and Oral Virulence of Salmonella enterica serovar Typhimurium. Infect. Immun. 2000, 68, 6139-6146.

22. Vogel, S. N.; Madonna, G. S.; Wahl, L. M.; Rick, P. D. In vitro Stimulations C3H/HeJ Spleen Cells and Macrophages by a Lipid A Precursor Molecule Derived from Salmonella typhimurium. J. Immunol. 1984, 132, 347-353.

23. Perry, R. D.; Fetherston, J. D. Yersinia pestis Etiologic Agent of Plague Clin. Microbiol. Rev. 1997, 10, 35-66.

24. Rebeil, R.; Ernst, R. K.; Gowen, B. B.; Miller, S. I.; Hinnebusch, B. J. Variation in Lipid A Structure in the Pathogenic Yersiniae. Mol. Microbiol. 2004, 52, 1363-1373.

25. Kawahara, K.; Tsukano, H.; Watanabe, H.; Lindner, B.; Matsuura, M. Modification of the Structure and Activity of Lipid A in Yersinia pestis Lipopolysaccharide by Growth Temperature. Infect. Immun. 2002, 70, 4092-4098.

26. Knirel, Y. A.; Lindner, B.; Vinogradov, E. V.; Kocharova, N. A.; Senchenkova, S. N.; Shaikhutdinova, R. Z.; Dentoyskava, S. V.; Fursova, N. K.; Bakteeva, I. V.; Titareva, G. M.; Balakhonov, S. V.; Holst, O.; Gremvakova, T. A.; Pier, G. B.; Anisimov, A. P. TemperatureDependent Variations and Intra-Species Diversity of the Structure of the Lipopolysaccharide of Yersinia pestis. Biochemistry 2005, 44, 1731-1743.

27. Rebeil, R.; Ernst, R. K.; Jarrett, C. O.; Adams, K. N.; Miller, S. I.; Hinnebusch, B. J. Characterization of Late Acyltransferase Genes of Yersinia pestis and Their Role in Temperature-Dependent Lipid A Variation. J. Bacteriol. 2006, 188, 1381-1388.

28. Aussel, L.; Therisod, H.; Karibian, D.; Perry, M. B.; Bruneteau, M.; Caroff, M. Novel Variation of Lipid A Structures in Strains of Different Yersinia Species. FEBS Lett. 2000, 465, 87-92.

29. Jones, J. W.; Shaffer, S. A.; Ernst, R. K.; Goodlett, D. R.; Turecek, F. Determination of Pyrophosphorylated Forms of Lipid A in GramNegative Bacteria using a Multivaried Mass Spectrometric Approach. Proc. Natl. Acad. Sci. U.S.A. 2008, 105, 12742-12747.

30. Une, T.; Brubaker, R. R. In Vivo Comparison of Avirulent Vwa- and Pgm- or Pstr Phenotypes of Yersiniae. Infect. Immun. 1984, 43, 895-900. 
31. Wang, X.; Karbarz, M. J.; McGrath, S. C.; Cotter, R. J.; Raetz, C. R. H. MBSA Transporter Dependent Lipid A 1-Dephosphorylation on the Periplasmic Surface of the Inner Membrane: Topography of Francisella novicida LpxE Expressed in Escherichia coli. J. Biol. Chem. 2004, 279, $49470-49478$

32. Wang, X.; McGrath, S. C.; Cotter, R. J.; Raetz, C. R. H. Expression Cloning and Periplasmic Orientation of the Francisella novicida Lipid A 4'-Phosphatase LpxF. J. Biol. Chem. 2006, 281, 9321-9330.

33. Westphal, O.; Jann, K. Bacterial Lipopolysaccharides: Extraction with Phenol-Water and Further Applications of the Procedure. Methods Carbohydr. Chem. 1965, 5, 83-91.

34. Fischer, W.; Koch, H. U.; Hass, R. Improved Preparation of Lipoteichoic Acids. Eur. J. Biochem. 1983, 133, 523-530.

35. Caroff, M.; Tacken, A.; Szabo, L. Detergent-Accelerated Hydrolysis of Bacterial Endotoxins and Determinations of the Anomeric Configuration of the Glycosyl Phosphate Present in the "Isolated Lipid A" Fragment of the Bordetella pertussis Endotoxin. Carbohydr. Res. 1998, 175, 273-282.

36. Domon, B.; Costello, C. E. Systematic Nomenclature for Carbohydrate Fragmentations in FAB-MS/MS Spectra of Glycoconjugates. Glycoconjugate 1988, 5, 397-409.

37. Koivusalo, M.; Haimi, P.; Heikinheimo, L.; Kostiainen, R.; Somerharju, P. Quantitative Determination of Phospholipid Compositions by ESIMS: Effects of Acyl Chain Length, Unsaturation, and Lipid Concentration on Instrument Response. J. Lipid Res. 2001, 42, 663-672.

38. Shaffer, S. A.; Harvey, M. D.; Goodlett, D. R.; Ernst, R. K. Structural Heterogeneity and Environmentally Regulated Remodeling of Francisella tularensis Subspecies Novicida Lipid A Characterized by Tandem Mass Spectrometry. J. Am. Soc. Mass Spectrom. 2006, 18, 1080-1092.

39. (a) Suda, Y.; Ogawa, T.; Kashihara, W.; Oikawa, M.; Shimoyama, T.; Hayashi, T.; Tamura, T.; Kusumoto, S. Chemical Structure and Biological Activity of a Lipid A Component from Helicobacter pylori Strain 206. J. Endotoxin Res. 2001, 7, 95-104. (b) Moran, A. P.; Lindner, B.; Walsh, E. J. Structural Characterization of the Lipid A Component of Helicobacter pylori Rough- and Smooth-Form Lipopolysaccharides. J. Bacteriol. 1997, 179, 6453-6463. (c) Tran, A. X.; Whittimore, J. D.; Wyrick, P. B.; McGrath, S. C. Cotter, R. J : Trent, M. S. The lipid A 1-Phosphatase of Helicobacter pylori Is Required for Resistance to the Antimicrobial Peptide Polymyxin. J. Bacteriol. 2006, 188, 4531-4541. (d) Tran, A. X.; Karbarz, M. J.; Wang, X.; Raetz, C. R. H.; McGrath, S. C.; Cotter, R. J.; Trent, M. S. Periplasmic Cleavage and Modification of the 1-Phosphate Group of Helicobacter pylori lipid A. J. Biol. Chem. 2004, 279, 55780-55791.

40. Tanamota, K.; Kato, H.; Haishima, Y.; Azumi, S. Biological Properties of Lipid A Isolated from Flavobacterium meningosepticum. Clin. Diagn. Lab. Immunol. 2001, 8, 522-527.

41. Weintraub, A.; Zahringer, U.; Wollenweber, H. W.; Seydel, U.; Rietschel, E. T. Structural Characterization of the Lipid A Component of Bacteroides fragilis strain NCTC 9343. Eur. J. Biochem. 1989, 183, 425-431.

42. Krasikova, I. N.; Kapustina, N. V.; Isakov, V. V.; Dmitrenok, A. S.; Dmitrenok, P. S.; Gorshkova, N. M.; Solov'eva, T. F. Detailed Structure of Lipid A Isolated from Lipopolysaccharide from the Marine Proteobacterium Marinomonas vaga ATCC 27119. Eur. J. Biochem. 2004, 271, 2895-2904.

43. Que-Gerwirth, N. L.; Ribeiro, A. A.; Kalb, S. R.; Cotter, R. J.; Bulach, D. M.; Adler, B.; Saint Girons, I.; Werts, C.; Raetz, C. R. H. A Methylated Phosphate Group and Four Amide-Linked Acyl Chains in Leptospira interrogans Lipid A. The Membrane Anchor of an Unusual Lipopolysaccharide that Activates TLR2. J. Biol. Chem. 2004, 279, 25410-25429.

44. (a) Kumada, H.; Haishima, Y.; Umemoto, T.; Tanamoto, K. Structural Study on the Free Lipid A Isolated from Lipopolysaccharide of Porphyromonas gingivalis. J. Bacteriol. 1995, 177, 2098-2106. (b) Ogawa, T. Chemical Structure of Lipid A from Porphyromonas (Bacteroides) gingivalis Lipopolysaccharides. FEBS Lett. 1993, 332, 197-201.
45. (a) Phillips, N. J.; Schilling, B.; McLendon, M. K.; Apicella, M. A.; Gibson, B. W. Novel Modifications of Lipid A of Francisella tularensis. Infect. Immun. 2004, 72, 5340-5348. (b) Vinogradov, E.; Perry, M. B.; Conlan, J. W. Structural Analysis of Francisella tularensis Lipopolysaccharide. Eur. J. Biochem. 2002, 269, 6112-6118. (c) Wang, X.; Ribeiro, A. A.; Guan, Z.; McGrath, S. C.; Cotter, R. J.; Raetz, C. R. H. Structure and Biosynthesis of Free Lipid A Molecules that Replace Lipopolysaccharide in Francisella tularensis subsp. ovicida. Biochemistry 2006, 45, 14427-14440. (d) Wang, X.; Ribeiro, A. A.; Guan, Z.; Abraham, S. N.; Raetz, C. R. H. Attenuated Virulence of a Francisella Mutant Lacking the Lipid A 4'-Phosphatase. Proc. Natl. Acad. Sci. U.S.A. 2007, 104, 41364141.

46. Boue, S. M.; Cole, R. B. Confirmation of the Structure of Lipid A from Enterobacter agglomerans by Electrospray Ionization Tandem Mass Spectrometry. J. Mass Spectrom. 2000, 35, 361-368.

47. Choma, A.; Sowinski, P. Characterization of Mesorhizobium huakuii Lipid A Containing Both D-Galacturonic Acid and Phosphate Residues. Eur. J. Biochem. 2004, 271, 1310-1322.

48. Plotz, B. M.; Lindner, B.; Stetter, K. O.; Holst, O. Characterization of a Novel Lipid A Containing D-Galacturonic Acid that Replaces Phosphate Residues. The Structure of the Lipid A of the Lipopolysaccharide from the Hyperthermophilic Bacterium Aquifex pyrophilus. J. Biol. Chem. 2000, 275, 11222-11228.

49. Bhat, U. R.; Forsberg, L. S.; Carlson, R. W. Structure of Lipid A Component of Rhizobium leguminosarum bv. Phaseolin Lipopolysaccharide. Unique Nonphosphorylated Lipid A Containing 2-Amino-2Deoxygluconate, Galacturonate, and Glucosamine. J. Biol. Chem. 1994, 269, 14402-14410.

50. (a) Que, N. L. S.; Ribeiro, A. A.; Raetz, C. R. H. Two-Dimensional NMR Spectroscopy and Structures of Six Lipid A Species from Rhizobium etli CE3. Detection of an Acyloxyacyl Residue in Each Component and Origin of the Aminogluconate Moiety. J. Biol. Chem. 2000, 275, $28017-$ 28027. (b) Que, N. L. S.; Lin, S.; Cotter, R. J.; Raetz, C. R. H. Purification and Mass Spectrometry of Six Lipid A Species from the Bacterial Endosymbiont Rhizobium etli. Demonstration of a Conserved Distal Unit and a Variable Proximal Portion. J. Biol. Chem. 2000, 275, 28006-28016.

51. Schwudke, D.; Linscheid, M.; Strauch, E.; Appel, B.; Zahringer, U.; Moll H.; Muller, M.; Brecker, L.; Gronow, S.; Lindner, B. The Obligate Predatory Bdellovibrio bacteriovorus Possesses a Neutral Lipid A Containing D-Mannoses that Replace Phosphate Residues: Similarities and Differences Between the Lipid As and the Lipopolysaccharides of the Wild Type Strain B. bacteriovorus HD100 and Its Host-Independent Derivative HI100. J. Biol. Chem. 2003, 278, 27502-27512.

52. Schromm, A. B.; Brandenburg, K.; Loppnow, H.; Moran, A. P.; Koch, M. H.; Rietschel, E. T.; Seydel, U. Biological Activities of Lipopolysaccharides are Determined by the Shape of Their Lipid A Portion. Eur. J. Biochem. 2000, 267, 2008-2013.

53. Qureshi, N.; Takayama, K.; Ribi, E. Purification and Structural Determination of Nontoxic Lipid A Obtained from the Lipopolysaccharide of Salmonella typhimurium. J. Biol. Chem. 1982, 257, 11808-11815.

54. Sasaki, S.; Tsuji, T.; Hamajima, K.; Fukushima, J.; Ishii, N.; Kaneko, T.; Xin, K. Q.; Mohri, H.; Aoki, I.; Okubo, T.; Nishioka, K.; Okuda, K. Monophosphoryl Lipid A Enhances Both Humoral and Cell-Mediated Immune Responses to DNA Vaccination Against Human Immunodeficiency Virus Type 1. Infect. Immun. 1997, 65, 3520-3528.

55. Persing, D. H.; Coler, R. N.; Lacy, M. J.; Johnson, D. A.; Baldridge, J. R.; Hershberg, R. M.; Reed, S. G. Taking Toll: Lipid A Mimetics as Adjuvants and Immunomodulators. Trends Microbiol. 2002, 10, S32-S37.

56. Ismaili, J.; Rennesson, J.; Aksov, E.; Vekemans, J.; Vincart, B.; Amraoui, Z.; Van Laethem, F.; Goldman, M.; Dubois, P. M. Monophosphoryl Lipid A Activates Both Human Dendritic Cells and T Cells. J. Immunol. 2002, 168, 926-932. 